\title{
Warm Conveyor Belts in the ERA-Interim Dataset (1979-2010). Part I: Climatology and Potential Vorticity Evolution
}

\author{
ERICA Madonna, Heini Wernli, And Hanna JoOs \\ Institute for Atmospheric and Climate Science, ETH Zurich, Zurich, Switzerland \\ Olivia MARTIUS \\ Oeschger Centre for Climate Change Research and Institute of Geography, University of Bern, Bern, Switzerland
}

(Manuscript received 1 October 2012, in final form 17 July 2013)

\begin{abstract}
A global climatology of warm conveyor belts (WCBs) is presented for the years 1979-2010, based on trajectories calculated with Interim ECMWF Re-Analysis (ERA-Interim) data. WCB trajectories are identified as strongly ascending air parcels ( $600 \mathrm{hPa}$ in 2 days) near extratropical cyclones. Corroborating earlier studies, WCBs are more frequent during winter than summer and they ascend preferentially in the western ocean basins between $25^{\circ}$ and $50^{\circ}$ latitude. Before ascending, WCB trajectories typically approach from the subtropics in summer and from more midlatitude regions in winter. Considering humidity, cloud water, and potential temperature along WCBs confirms that they experience strong condensation and integrated latent heating during the ascent (typically $>20 \mathrm{~K}$ ). Liquid and ice water contents along WCBs peak at about 700 and $550 \mathrm{hPa}$, respectively. The mean potential vorticity (PV) evolution shows typical tropospheric values near $900 \mathrm{hPa}$, followed by an increase to almost 1 potential vorticity unit (PVU) at $700 \mathrm{hPa}$, and a decrease to less than $0.5 \mathrm{PVU}$ at $300 \mathrm{hPa}$. These low $\mathrm{PV}$ values in the upper troposphere constitute significant negative anomalies with amplitudes of 1-3 PVU, which can strongly influence the downstream flow. Considering the low-level diabatic PV production, (i) WCBs starting at low latitudes $\left(<40^{\circ}\right)$ are unlikely to attain high PV (due to weak planetary vorticity) although they exhibit the strongest latent heating, and (ii) for those ascending at higher latitudes, a strong vertical heating gradient and high absolute vorticity are both important. This study therefore provides climatological insight into the cloud diabatic formation of significant positive and negative $\mathrm{PV}$ anomalies in the extratropical lower and upper troposphere, respectively.
\end{abstract}

\section{Introduction}

Extratropical cyclones are everyday phenomena that can cause adverse weather and significantly impact our climate. They are an important component of the atmospheric general circulation since they transfer large amounts of heat, moisture, and momentum poleward (e.g., Hartmann 1994; Holton 2004). Studies on extratropical cyclones and the structure of their cloud and precipitation distributions go back to the nineteenth and early twentieth century, when the classical Norwegian polar-front theory emphasized the role of preexisting surface fronts for cyclone development and the formation of precipitation (Bjerknes and Solberg 1922). Although

Corresponding author address: Erica Madonna, Institute for Atmospheric and Climate Science, Universitätstrasse 16, ETH Zürich, CH-8092 Zürich, Switzerland.

E-mail: erica.madonna@env.ethz.ch many modifications and extensions have become necessary in the following years, this concept has served as a cornerstone of synoptic meteorology until today, since it offers a coherent framework for a unified view of the processes and evolution of cyclonic weather systems (Reed 1990; Friedman 1999).

Later, isentropic analyses of the airflow in a coordinate system moving with the cyclone evidenced the presence of three distinct airstreams associated with extratropical cyclones: the dry intrusion (e.g., Reed and Danielsen 1959), the warm conveyor belt (WCB; e.g., Green et al. 1966; Harrold 1973; Browning et al. 1973), and the cold conveyor belt (e.g., Carlson 1980). These airstreams build the quasi-Lagrangian conveyor belt model, which is particularly useful for the interpretation of satellite imagery [see the overview articles by Browning (1990) and Browning and Roberts (1994)]. Additional evidence for the existence of conveyor belts was provided by Wernli and Davies (1997) and Wernli (1997), who 
used a fully Lagrangian approach based on trajectory calculations and objective selection criteria in order to identify coherent ensembles of trajectories with distinct physical properties. It was found that the dry intrusion can be identified as an ensemble of trajectories characterized by maximum descent (Wernli 1997). Similarly, the WCB can be identified objectively as a trajectory ensemble characterized by maximum ascent, increase in potential temperature, or decrease in specific humidity integrated along trajectories during a time period of two days, a time period comparable to the growth phase of extratropical cyclones. In other words, WCBs correspond to intense cross-isentropic (i.e., diabatic) airflows. In recent years, several studies used such a Lagrangian approach to identify WCBs (see below).

In this climatological study we focus on WCBs. They are particularly relevant as they transport large quantities of sensible and latent heat upward and poleward, and they are the primary cloud-producing extratropical flow structure responsible for the major part of precipitation associated with extratropical cyclones (Browning 1990). WCBs usually have their origin in the moist subtropical marine boundary layer between $20^{\circ}$ and $45^{\circ}$ (Wernli and Davies 1997) and are more frequent in winter than in summer, as found in the pioneering climatologies of WCBs (Stohl 2001; Eckhardt et al. 2004). WCBs are also relevant for atmospheric chemistry. Because of their rapid ascent to the upper troposphere, WCBs originating over (or downstream of) continents can transport high concentrations of ozone (and other pollutants) from the boundary layer to the upper troposphere and consequently influence the chemical composition in the free troposphere (Arnold et al. 1997; Bethan et al. 1998; Stohl and Trickl 1999; Stohl 2001). On the time scale of a few days, WCBs can transport pollution from one continent to another (Stohl et al. 2002). Sinclair et al. (2008) pointed out that WCBs are the dominant advective transport mechanism for boundary layer ventilation and transport into the free troposphere. According to trajectory calculations using reanalysis data, some WCB trajectories cross the tropopause (Stohl 2001; Eckhardt et al. 2004) and therefore influence atmospheric composition also in the lowermost stratosphere.

In addition to the key role of WCBs for the formation of precipitation and the transport of atmospheric constituents, they are highly relevant from a dynamical point of view. It is attractive to study the dynamical influence of WCBs from the potential vorticity (PV) perspective, since WCBs influence the tropospheric PV distribution in different ways. The PV modification within WCBs is a central aspect of this study. According to, for example, Hoskins et al. (1985) and Haynes and
McIntyre (1987), latent heat release due to condensation (which is very pronounced within WCB flows) leads to the material production and destruction of PV. Defining $\mathrm{PV}$ in pressure coordinates

$$
\mathrm{PV}=-g \boldsymbol{\eta} \cdot \nabla_{p} \theta
$$

where $g$ is the acceleration due to gravity and $\boldsymbol{\eta}=f \mathbf{k}+\nabla_{p} \times \mathbf{v}$ is the absolute vorticity in pressure coordinates ( $f$ is the Coriolis parameter and $\mathbf{v}$ the horizontal wind on a pressure surface), the Lagrangian rate of change of potential vorticity $(D / D t) \mathrm{PV}$ can be expressed as follows:

$$
\frac{D}{D t} \mathrm{PV}=-g \boldsymbol{\eta} \cdot \nabla_{p} \dot{\theta}
$$

where $\dot{\theta}$ is the diabatic heating rate. Frictional processes are neglected in the above equation. Under the assumption that the vertical gradient of the diabatic heating rate dominates, it follows that $\mathrm{PV}$ is generated below the level of maximum diabatic heating (decrease of $\dot{\theta}$ with pressure) and is destroyed above, assuming a positive vertical component of absolute vorticity (Stoelinga 1996). Wernli (1997) studied the evolution of PV along several WCBs and observed low PV values $[\sim 0.5 \mathrm{PVU} ; 1$ potential vorticity unit $(\mathrm{PVU})=$ $10^{-6} \mathrm{~K} \mathrm{~m}^{2} \mathrm{~kg}^{-1} \mathrm{~s}^{-1}$ ] in the WCB inflow in the lower troposphere, followed by an increase to more than 1 PVU in the midtroposphere and a successive decrease to 0.5 PVU or less in the WCB outflow in the upper troposphere. Similar results are reported by Wernli and Davies (1997) for a set of North Atlantic WCBs in January 1993. The detailed mesoscale modeling study by Joos and Wernli (2012) confirmed this behavior of PV along a WCB and emphasized the importance of different microphysical processes such as condensation and depositional growth of snow for the diabatic PV modification. The positive PV anomaly, which forms in the midtroposphere, is regarded to be important for the evolution of the cyclone and its intensity (Davis and Emanuel 1991; Stoelinga 1996), in particular if the WCB ascent occurs close to the cyclone center. In other cases, the WCB ascent is located along the cold front (i.e., relatively far away from the cyclone center), and in these cases the effect of the diabatically produced positive PV anomaly is mainly to increase the poleward advection of warm and moist air (Lackmann 2002).

Negative PV anomalies occur in the WCB outflow regions in the upper troposphere at the level of the midlatitude jet stream. These anomalies can enhance the amplitude of upper-level ridges (Pomroy and Thorpe 2000), which in turn can be key for the downstream 
amplification and the breaking of upper-level Rossby waves (Massacand et al. 2001). The downstream wave breaking can lead to the formation of PV streamers, which can act as precursors of heavy precipitation events (e.g., Massacand et al. 1998; Knippertz and Martin 2005; Martius et al. 2006). This has been illustrated in some detail in a North Atlantic case study by Grams et al. (2011), who found that the negative upper-level PV anomaly enhanced by the WCB contributed first to the ridge building downstream of the $\mathrm{WCB}$ and then to the subsequent formation of a PV streamer, which triggered Mediterranean cyclogenesis and intense precipitation. A similar effect of WCBs at the outflow level was found by Schemm et al. (2013), who studied the PV evolution along WCBs within an idealized moist baroclinic wave.

This brief overview on the one hand highlights the importance of WCBs for the evolution of midlatitude weather systems and their associated precipitation and, on the other hand, emphasizes the complex interaction of physical and dynamical processes associated with WCBs, which have not yet been fully investigated on a climatological basis. So far, only a few studies have investigated the frequency distribution and interannual variability of WCBs. Wernli and Davies (1997) objectively identified WCBs in the Northern Hemisphere during January 1993 and found that they are frequent features of the midlatitude wintertime circulation with, on average, an integrated latent heating of more than 20 K. Stohl (2001) and Eckhardt et al. (2004) used the 15-yr European Centre for Medium-Range Weather Forecasts (ECMWF) Re-Analysis (ERA-15) dataset (1979-93) to produce the first global climatologies of WCBs. Given the importance of WCBs, it is the aim of this two-part paper to use a state-of-the-art reanalysis dataset to investigate in detail their climatological characteristics. This first paper focuses on the objective identification of WCBs, the seasonal and regional variations of their frequency of occurrence, and the evolution of key properties, in particular PV, along these airstreams. The second part of this study (Pfahl et al. 2013, hereafter Part II) investigates novel aspects of WCBs, in particular their evaporative moisture sources and their relevance for precipitation in general and extreme precipitation events in particular.

In section 2, the method of objectively identifying WCBs is explained, which is a refined approach of the one previously used by, for instance, Wernli and Davies (1997) and Eckhardt et al. (2004). In section 3 the global climatology of WCBs is presented for the years 19792010. An analysis of the evolution of different parameters along the WCB trajectories is then discussed in section 4 , and section 5 presents a detailed discussion of the diabatic PV modification along WCBs. A discussion about potential limitations of the study and the main conclusions follow in section 6 .

\section{Data and methods}

\section{a. Calculation of trajectories}

The calculation of the WCB trajectories is based on the Interim ECMWF Re-Analysis (ERA-Interim) dataset (Simmons et al. 2006; Dee et al. 2011) and the Lagrangian Analysis Tool (LAGRANTO; Wernli and Davies 1997). LAGRANTO calculates three-dimensional kinematic trajectories, using the three-dimensional analysis wind fields with an iterative predictor-corrector procedure and a computational time step of $30 \mathrm{~min}$. Fields from ERA-Interim are available every $6 \mathrm{~h}$ and on 60 vertical levels (from the surface to $0.1 \mathrm{hPa}$ ) and have been interpolated from T255 spectral resolution to a regular grid with $1^{\circ}$ horizontal resolution. The considered time period extends from 1979 to 2010.

Every $6 \mathrm{~h}, 2$-day forward trajectories were started from a set of starting points in the lower troposphere. Horizontally the starting points are located every $80 \mathrm{~km}$ and vertically every $20 \mathrm{hPa}$ within the layer from 1050 to $790 \mathrm{hPa}$, leading to more than 800000 trajectories per time step, which represent the flow of the entire lowermost troposphere. The identified 2-day WCB trajectories (see next subsection) are then extended 10 days backward and forward, yielding a total trajectory duration of 22 days. Along these trajectories, a comprehensive set of variables is traced, together with trajectory position (longitude and latitude) and pressure. These variables are specific humidity $q$, cloud liquid and ice water content (LWC and IWC, respectively), relative humidity (RH), potential temperature $\theta$, and potential vorticity. The variables RH, $\theta$, and PV have been calculated previously from the primary model-level dataset.

\section{b. WCB selection criteria}

To identify WCB trajectories, a Lagrangian selection criterion based on the rapid ascent of WCB trajectories is used similar to previous studies (e.g., Wernli and Davies 1997; Eckhardt et al. 2004). In this study the criterion of ascent from the lowermost troposphere (extending from the surface to $790 \mathrm{hPa}$ ) of more than $600 \mathrm{hPa}$ within 2 days is used. Wernli and Davies (1997) showed that this simple geometric criterion leads to similar results to criteria focusing on a large increase in potential temperature or decrease of specific humidity. This criterion of ascent exceeding $600 \mathrm{hPa}$ within 2 days is fairly strong. In all situations where some trajectories fulfill this criterion, there is an even larger number of trajectories that are characterized by a weaker ascent 


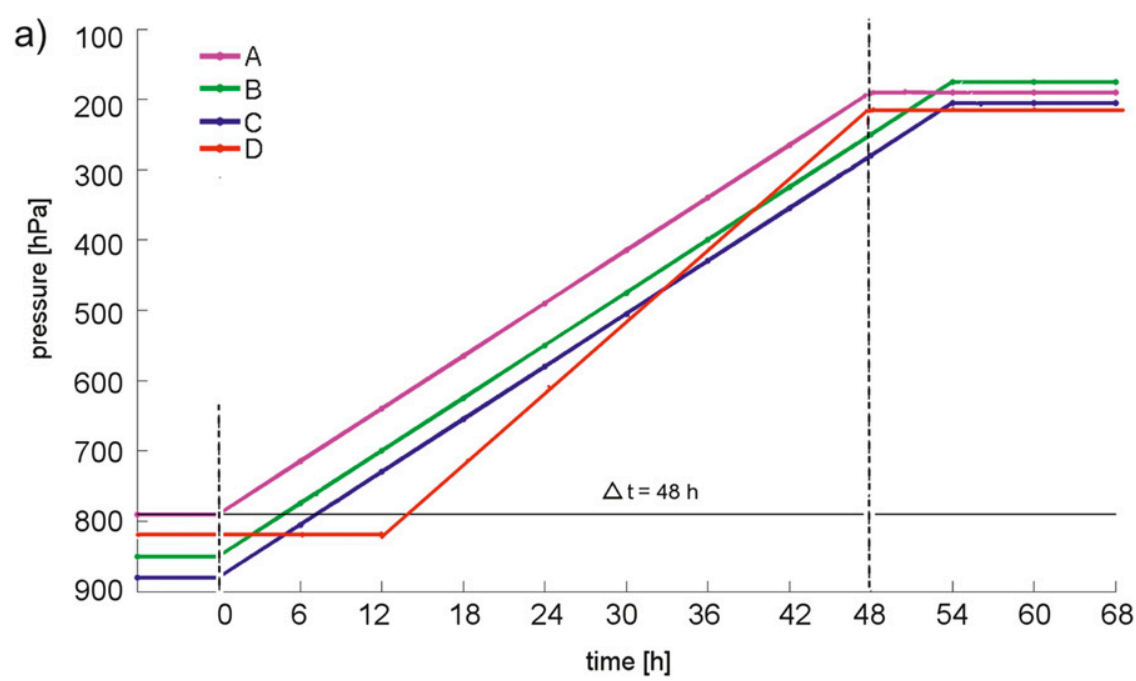

b)

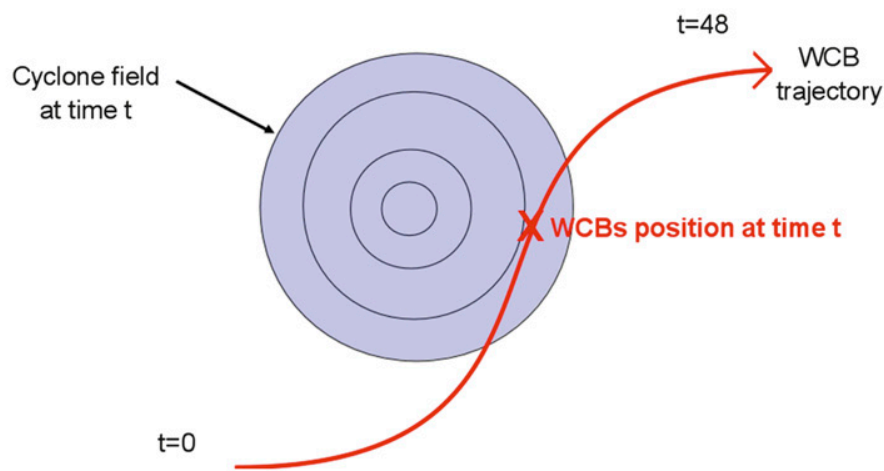

FIG. 1. (a) Schematic to explain the filter criterion that avoids the double counting of WCB trajectories. Trajectories A and B are identified as potential WCB trajectories during the time period $t=0-48 \mathrm{~h}$, trajectory C during $t=6-54 \mathrm{~h}$, and trajectory D during $t=12-60 \mathrm{~h}$ (see text for details). (b) Schematic to illustrate the procedure to check the match between WCB trajectories and surface cyclones. At least at one 6-hourly time step the WCB trajectory must be located within a two-dimensional cyclone field.

(e.g., $500 \mathrm{hPa}$ ) within the same time period. This indicates that our criterion focuses on the trajectories with maximum integrated ascent (and the strongest diabatic heating), which are most relevant for modifying the upper-tropospheric flow at the jet stream level, as discussed in the introduction. However, we do not aim at identifying the entire air mass ascending in the warm sector of an extratropical cyclone.

With our setup of starting the trajectories globally in the low troposphere every $6 \mathrm{~h}$, this Lagrangian selection criterion of maximum ascent is not sufficient to obtain a robust climatology of WCBs. Two additional filters have to be applied to the trajectories that fulfill the $600-\mathrm{hPa}$ ascent criterion, the first to avoid a double counting of WCB trajectories and the second to make sure that the ascent occurs in the vicinity of an extratropical cyclone. Rapid and deep ascent occurs also, for example for trajectories within summertime continental convection, and they should not be classified as WCBs. The two filters are explained in the following paragraphs.

A double counting of WCB trajectories can occur, for instance, if the $600-\mathrm{hPa}$ ascent occurs during a shorter period than the overall trajectory integration of $48 \mathrm{~h}$. In such a situation, the same air mass fulfills the selection criterion for different starting times. Therefore, a filter has been designed to consider such rapidly ascending trajectories only during the last 2-day time period for which the ascent criterion is fulfilled. (Our results do not depend on this choice of considering these trajectories during the last time period, but it is important to only count them once.) Figure 1a illustrates this selection procedure. Trajectory A represents an unproblematic case, where the air parcel starts in the boundary layer at $t=0 \mathrm{~h}$, rises above the $790-\mathrm{hPa}$ level at $t=6 \mathrm{~h}$, and 
reaches a total ascent of $600 \mathrm{hPa}$ after $48 \mathrm{~h}$ when it stops rising. Clearly, this trajectory only fulfills the ascent criterion during the time period $t=0-48 \mathrm{~h}$. The same is true for trajectory $\mathrm{B}$, which continues to ascend after $t=$ $48 \mathrm{~h}$. This trajectory also rises more than $600 \mathrm{hPa}$ during $t=6-54 \mathrm{~h}$, but at $t=6 \mathrm{~h}$ it is already located above the 790-hPa level. Therefore, since we only start trajectories at pressure levels larger than $790 \mathrm{hPa}$, this trajectory is not calculated during the $t=6-54 \mathrm{~h}$ period and no double-counting problem occurs. In contrast, trajectory $\mathrm{C}$ fulfills the ascent criterion during the 2-day periods from $t=0-48 \mathrm{~h}$ and $t=6-54 \mathrm{~h}$, because at $t=6 \mathrm{~h}$ the trajectory is still located at $p>790 \mathrm{hPa}$. The filter therefore eliminates trajectory $\mathrm{C}$ as a WCB trajectory for the first of these time periods and keeps it during the second period. ${ }^{1}$ Trajectory $\mathrm{D}$ represents a very rapidly ascending WCB trajectory, which fulfills the selection criterion during three 2-day periods when $t=0-48 \mathrm{~h}, t=$ $6-54 \mathrm{~h}$, and $t=12-60 \mathrm{~h}$. Our choice is to only consider this trajectory during the last of these periods (i.e., from $t=12$ to $60 \mathrm{~h}$ ). The effect of our choice is that all selected WCB trajectories start to ascend at the beginning of their 2-day period and that their vertical position might be less coherent toward the end of this period (e.g., trajectory $\mathrm{D}$ reaches maximum altitude already after $36 \mathrm{~h}$, whereas this occurs after $48 \mathrm{~h}$ for trajectories A and $\mathrm{C}$, and after $54 \mathrm{~h}$ for trajectory B).

In addition, we require that the ascent of WCB trajectories occur in the vicinity of an extratropical cyclone. This allows us to separate upward motion associated with WCBs in extratropical cyclones from deep convective systems in the tropics and extratropics. For this second filter, we consider the trajectory positions relative to the position of extratropical cyclones. To identify cyclones, the method described by Wernli and Schwierz (2006) (with a few modifications) is used. This method identifies surface cyclones as two-dimensional features, which contain one (or several) local sea level pressure (SLP) minima enclosed by the outermost closed SLP contour. The 6-hourly SLP fields from the ERA-Interim dataset are used to obtain a global climatology of surface cyclones. The modifications with respect to the original method (Wernli and Schwierz 2006) are as follows: 1) starting from every local SLP minimum, closed isobars are identified at intervals of $0.5 \mathrm{hPa}$ (instead of $2 \mathrm{hPa}$ ),

\footnotetext{
${ }^{1}$ To be precise we note that the considered trajectory started at $t=6 \mathrm{~h}$ is not exactly identical to the one starting at $t=0 \mathrm{~h}$ since the one at $t=6 \mathrm{~h}$ starts on the predefined starting grid, whereas the other starts on the same grid $6 \mathrm{~h}$ earlier and then, at $t=6 \mathrm{~h}$, might not be located exactly at a starting grid point. However, since in both cases our starting grid covers the entire lowermost troposphere, the two trajectories represent the same air mass.
}

which allows us to identify also very weak cyclones, and 2) cyclones that are close to each other (e.g., binary cyclones with two local SLP minima) are merged as long as the length of the outermost closed contour does not exceed $7500 \mathrm{~km}$. To exclude tropical cyclones, identified cyclones between $25^{\circ} \mathrm{N}$ and $25^{\circ} \mathrm{S}$ are not considered for the matching with the potential WCB trajectories. As illustrated in Fig. 1b, a trajectory is finally considered as a WCB trajectory if its horizontal position is located within a two-dimensional surface cyclone field for at least one 6-hourly time step during the 48-h ascent phase. This matching of the positions of the WCB and the cyclone at one time only might appear as a weak constraint. However, since some cyclones are rather small and WCBs can move rapidly, the one-time matching is appropriate.

From the 37 billion trajectories started during the 32 years, only $0.36 \%$ fulfill the $600-\mathrm{hPa}$ ascent criterion in 2 days. After the filtering procedures, only $1 / 6$ of these strongly ascending trajectories are retained as WCB trajectories, indicating the importance of the two filters. The final number of WCB trajectories investigated in this climatology then corresponds to more than 20 million.

\section{c. Illustration of the filtering procedure}

An example of the effect of the two filtering procedures is shown in Fig. 2 for trajectories starting at 1200 UTC 20 September 1993. Colored lines represent the 48-h trajectories that fulfill the $600-\mathrm{hPa}$ ascent criterion and black contours show the sea level pressure $24 \mathrm{~h}$ after the start of the trajectories. Trajectories that are eliminated by the first filter are shown in purple (e.g., over northern Europe). They are identified as WCB trajectories during a later 2-day time period. Mainly in the tropics bundles of ascending trajectories are found, which do not show a large horizontal displacement and which are far away from extratropical cyclones. They are eliminated by the second filter and shown in green. There are some green trajectories also in the extratropics, which, according to our procedure, are not directly related to a SLP minimum, for example to the east of Japan. It is likely that these trajectories ascend rapidly due to intense convection along the trailing cold front, too far from the cyclone center (i.e., outside of the cyclone region) to be classified as WCB trajectories. The remaining trajectories are classified as WCB trajectories and are colored with pressure. They form fairly coherent ensembles and reveal a fast poleward ascent. At upper levels $(\sim 300 \mathrm{hPa})$ they typically lose coherency. In the Southern Hemisphere (SH) we observe five WCBs distributed over all longitudes, starting between $20^{\circ}$ and $40^{\circ} \mathrm{S}$ and reaching as far poleward as $60^{\circ} \mathrm{S}$. In the Northern Hemisphere $(\mathrm{NH})$ four WCBs are identified, including a very intense one in the North Atlantic with an outflow 


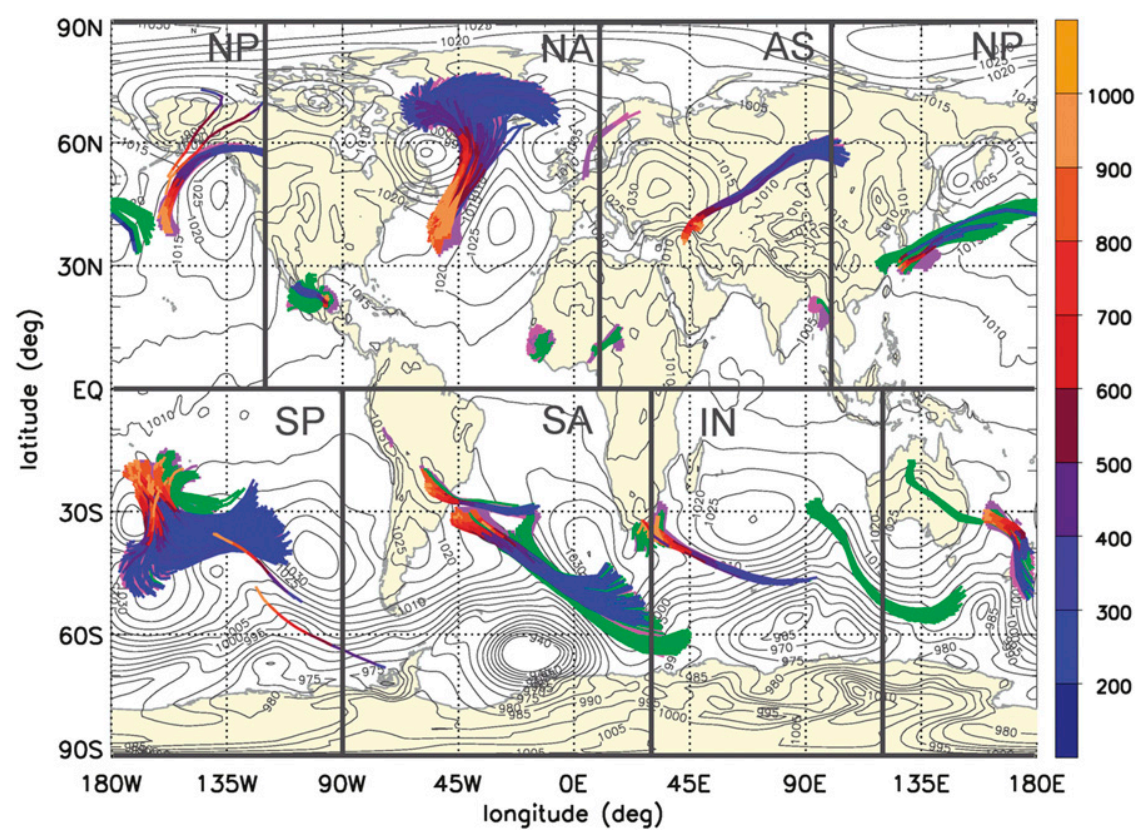

FIG. 2. Two-day trajectories started at 1200 UTC 20 Sep 1993 and SLP at 1200 UTC 21 Sep 1993 (black contours, every $5 \mathrm{hPa}$ ). The purple trajectories are those removed by the doublecounting filter whereas the green ones are removed by the cyclone identification filter. The remaining trajectories are colored with pressure and classified as WCB trajectories. The gray boxes are used for the analysis in section 4. The labels refer to the North Pacific (NP), North Atlantic (NA), western and central Asia (AS), the South Pacific (SP), South Atlantic (SA), and the Indian Ocean (IN).

reaching $80^{\circ} \mathrm{N}$. This example illustrates the filtering and indicates that the procedure is able to identify WCBs in a meaningful way.

One has to keep in mind that WCBs are threedimensional flow features that evolve in time. Some of the identified WCBs can last up to several days, meaning that a sequence of WCB trajectories can be identified during consecutive 6-hourly separated 2-day time periods, of course with an evolving starting region, shape, and outflow pattern. Such a time sequence was shown by Wernli (1997, their Fig. 12). For the example shown in Fig. 2, the feature in the North Atlantic (between $80^{\circ} \mathrm{E}$ and $0^{\circ}$ ) is identified for the first time at 1800 UTC 18 September and is detected until 0000 UTC 23 September. For instance, at 1200 UTC 20 September the WCB consists of 241 trajectories, which start (on average) at $911 \mathrm{hPa}$ and reach the 280 -hPa level after $48 \mathrm{~h}$. During their ascent they experience an averaged decrease of specific humidity of almost $12 \mathrm{~g} \mathrm{~kg}^{-1}$, a concomitant increase of potential temperature by $26 \mathrm{~K}$, and a PV evolution from initially $0.47 \mathrm{PVU}$ to a maximum of 0.81 PVU after $12 \mathrm{~h}$ followed by a decrease to $0.23 \mathrm{PVU}$ at $48 \mathrm{~h}$. Comparable values of these quantities have been found in previous studies of WCBs (e.g., Wernli 1997; Wernli and Davies 1997), which supports the reliability of our method to identify WCBs. Here we also like to note that these diabatic changes of $q$ and $\theta$ are consistent: the increase of $\theta$ is related to the decrease in $q$ by $\Delta \theta=-\left(p_{0} / p\right)^{\kappa}\left(L / c_{p}\right) \Delta q$, where $\kappa=0.286, L$ and $c_{p}$ denote the latent heat of condensation and the specific heat capacity of water, respectively, and $p_{0}$ is a reference pressure of $1000 \mathrm{hPa}$. Assuming that $12 \mathrm{~g} \mathrm{~kg}^{-1}$ of water vapor condense at an average pressure of $750 \mathrm{hPa}$ leads to an estimate of the concomitant increase of $\theta$ by about $32 \mathrm{~K}$, which is slightly higher than but qualitatively consistent with the observed $26 \mathrm{~K}$. For the diabatic PV modifications a simple estimate is difficult since it depends strongly on the detailed structure of the latent heating and vorticity fields, as discussed below.

\section{d. An example $W C B$}

Before proceeding to the climatological results, a brief case study is presented in order to illustrate the potential role of the low PV values in the WCB outflow for modifying the subsequent upper-level flow evolution downstream. We choose a WCB that preceded the formation of a severely damaging heavy precipitation event in southern Switzerland during 22-24 September 1993 (Massacand et al. 2001). [Further details of the event, which mainly affected the city of Brig (black star in 

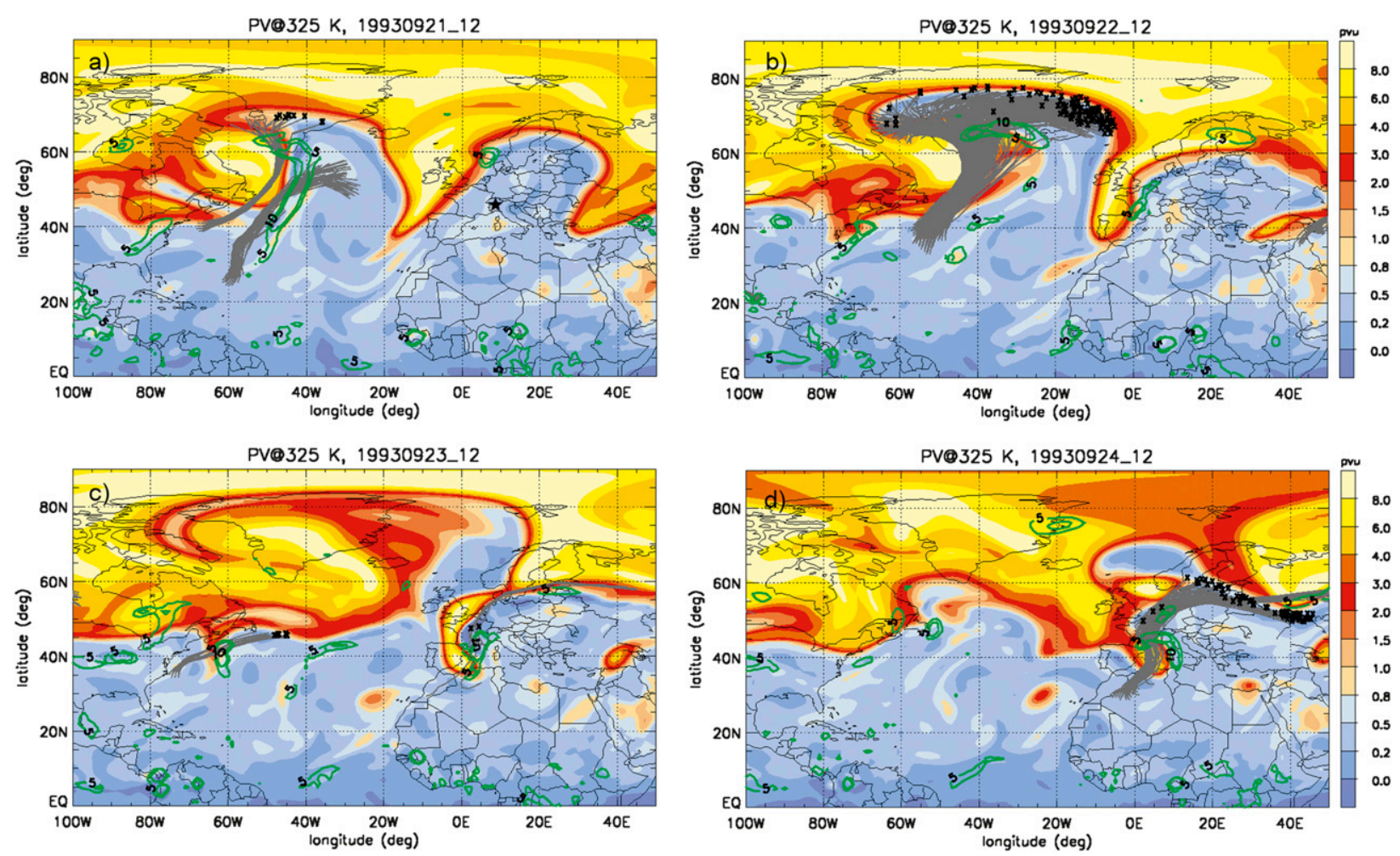

FIG. 3. Isentropic PV charts on 325 K, in 24-h intervals from 1200 UTC 21 Sep 1993 to 1200 UTC 24 Sep 1993. Green contours denote 6-hourly accumulated precipitation. WCB trajectories starting $48 \mathrm{~h}$ earlier are shown as gray lines and a black cross is drawn if the final WCB position is located above $325 \mathrm{~K}$.

Fig. 3a), can be found in the studies by, say, BAFU (1994) and Buzzi and Foschini (2000).] The presence of an intense, north-south aligned, and slowly moving upper-level PV streamer to the west of the Alps (see Figs. 3b,c) was a key factor leading to this event, as discussed by Massacand et al. (1998). Figure 3 shows the evolution of the PV structure on the $325-\mathrm{K}$ isentrope, together with 6-hourly accumulated precipitation (green contours) and the WCB trajectories (gray lines), daily from 1200 UTC 21 September to 1200 UTC 24 September. In every panel, the WCB trajectory positions at the end of the 2-day ascent are marked with a black symbol if they cross the $325-\mathrm{K}$ isentrope.

At 1200 UTC 21 September (Fig. 3a), a pronounced wave pattern extends from North America to eastern Europe, with a positive PV anomaly over the United Kingdom (the precursor of the PV streamer) and an intense upstream ridge over the central North Atlantic. At this time only few WCB trajectories in the western North Atlantic reach into this upper-level ridge and most of them do not reach the $325-\mathrm{K}$ level. One day later (Fig. 3b), the outflow of the now very intense North Atlantic WCB reaches $325 \mathrm{~K}$ and "fills" the almost entire upper-level ridge upstream of the elongating PV streamer over western Europe. The averaged PV value in the outflow of these WCB trajectories amounts to 0.23 PVU. This low PV, modified by diabatic processes within the WCB, enhances the upstream negative PV anomaly at $325 \mathrm{~K}$ and helps the streamer formation (see also Massacand et al. 2001). Twelve hours later (not shown), the effect is similarly strong. This potential key role of WCBs for the upper-level ridge amplification is the main reason for performing a detailed study of the PV evolution along WCBs on a climatological basis in sections 4 and 5 . On the subsequent day (Fig. 3c) there are no newly ascending WCB trajectories in the upper-level ridge, but the WCB-enhanced low-PV anomaly and the PV streamer farther south form a PV dipole, which is a fairly stationary flow configuration that can persist against the large-scale westerly advection. At 1200 UTC 24 September (i.e., at the time of heavy precipitation south of the Alps), a new WCB can be seen rising from North Africa to central Europe (Fig. 3d), which contributes in parts to the extreme precipitation. This aspect of the linkage between WCBs and heavy precipitation is further studied in the continuation paper (Part II). 


\section{WCB climatology: Geographical distribution and seasonal variations}

The procedure outlined above to calculate WCBs has been performed for all 2-day time periods during the 32 years from 1979 to 2010. For all identified WCB trajectories, their positions have been aggregated on a regular grid with $1^{\circ}$ horizontal resolution to obtain climatological WCB frequency fields, separately for the various seasons.

\section{a. WCBs starting regions}

Figures 4 and 5 show the 32-yr climatology of the geographical distribution of WCB frequencies for the seasons December-February (DJF) and June-August (JJA), respectively, for different stages during the WCB life cycle. The WCB starting points $(t=0)$ are shown in Figs. $4 \mathrm{~d}$ and $5 \mathrm{~d}$. The unit corresponds to the percentage of 6-hourly time steps during which at least one WCB trajectory is located somewhere in the vertical column represented by the grid point (e.g., at $t=0 \mathrm{~h}$ a value of 1 indicates that at $1 \%$ of the time instants during the considered period at least one WCB trajectory starts its 2-day ascent phase at this grid point). In both figures, panels a-c show the distribution of the WCB trajectories 144,96 , and $48 \mathrm{~h}$ before the start of the ascent, whereas panels e-h show WCB locations $24,48,96$, and $144 \mathrm{~h}$ after the start of the ascent. The $1 \%$ contour of the frequency field at $t=0 \mathrm{~h}$ is shown in all panels as a reference (black contour).

In agreement with the earlier climatologies by Stohl (2001) and Eckhardt et al. (2004), we find that WCBs are more frequent during winter than during summer. WCB starting regions (Figs. $4 \mathrm{~d}$ and $5 \mathrm{~d}$ ) are in the $\mathrm{NH}$ winter located between $22^{\circ}$ and $42^{\circ} \mathrm{N}$ and in summer in a larger latitudinal range between $20^{\circ}$ and $47^{\circ} \mathrm{N}$, whereas in the $\mathrm{SH}$ the starting points are situated between $17^{\circ}$ and $42^{\circ} \mathrm{S}$ in JJA and at similar locations, $19^{\circ}-42^{\circ} \mathrm{S}$, in DJF. Peak values occur near $30^{\circ} \mathrm{N}$ in the $\mathrm{NH}$ and farther equatorward in the $\mathrm{SH}$.

In the $\mathrm{NH}$ winter the $\mathrm{WCB}$ starting positions reveal two distinct maxima over the western North Atlantic and North Pacific, respectively (Fig. 4d). They are in agreement with the results of Eckhardt et al. (2004) and are located to the south of the winter storm track entrance regions as indicated by cyclone climatologies (e.g., Sickmöller et al. 2000; Wernli and Schwierz 2006). Note that the maximum frequency values reach almost $10 \%$, indicating that at $10 \%$ of all 6 -hourly time steps, WCBs ascend from these regions.

In the $\mathrm{NH}$ summer a large maximum (with peak values of $5 \%$ ) occurs over the western North Pacific, China, and Taiwan. This region is characterized by the nearly stationary low-level baroclinic zone, known as the mei-yu-baiu front, associated with a low-level jet and a strong meridional humidity gradient (Ding and Chan 2005; Ninomiya and Shibagaki 2007). Knippertz and Wernli (2010) suggested that the mei-yu-Baiu front, together with the East Asian monsoon, is responsible for tropical moisture exports over the west Pacific in summer. These ingredients favor strong ascent of low-level moist air masses and are able to explain the maximum in the WCB frequency during JJA in the west Pacific.

Monsoon precipitation is active over India in spring and summer. The strong continental warming compared to the adjacent ocean leads to thermal heat lows over the northern and central Indian subcontinent (Chen 2003). Strong low-level westerly jets, partially driven by the heat low, blow over the Arabian Sea and cyclonic vorticity over the Bay of Bengal is established (Lau et al. 2005). These moisture-laden winds rush into the subcontinent toward the Himalayas where they are forced to rise. As a result in March-May (not shown) and JJA a peak in the frequency of WCB starting points can be observed along the southern foothills of the Himalaya (with values $>7 \%$ ). This feature has not been found in the previous climatologies by Stohl (2001) and Eckhardt et al. (2004). In addition to requiring strong ascent, they applied a criterion that the trajectories have to move at least $5^{\circ}$ to the north and $10^{\circ}$ to the east in order to be considered as WCB trajectories. This geometric criterion eliminated the Himalayan WCBs, which show limited northward and eastward movement during JJA (on average $9^{\circ}$ to the east and $3^{\circ}$ to the north). We decided to not use such an additional criterion, first because it requires additional subjectively chosen thresholds, and second because we found several WCBs that are located to the west of their starting position after $48 \mathrm{~h}$, due to the strong cyclonic motion associated with the low pressure system.

In the $\mathrm{SH}$, zonal variability is weaker than in the $\mathrm{NH}$, in particular during winter (JJA), when the starting points are fairly equally distributed in the zonal direction with a maximum over South America and a minimum over Australia (Fig. 5d). In DJF (summer; Fig. 4d) the zonal variability is larger and WCBs are more likely to start to the east of the continents (South America, Africa, and Australia) and, with a distinct frequency peak again, over South America in the lee of the Andes [as found already by Eckhardt et al. (2004)]. This region is known as a considerable cyclogenesis zone throughout the year (e.g., Simmonds and Keay 2000; Vera et al. 2002; Wernli and Schwierz 2006). As shown by Mendes et al. (2007), the presence of the Andes plays a major role in controlling the location of cyclones. Additionally, because of the topography a northerly low-level jet is established through mechanical forcing (e.g., Campetella 

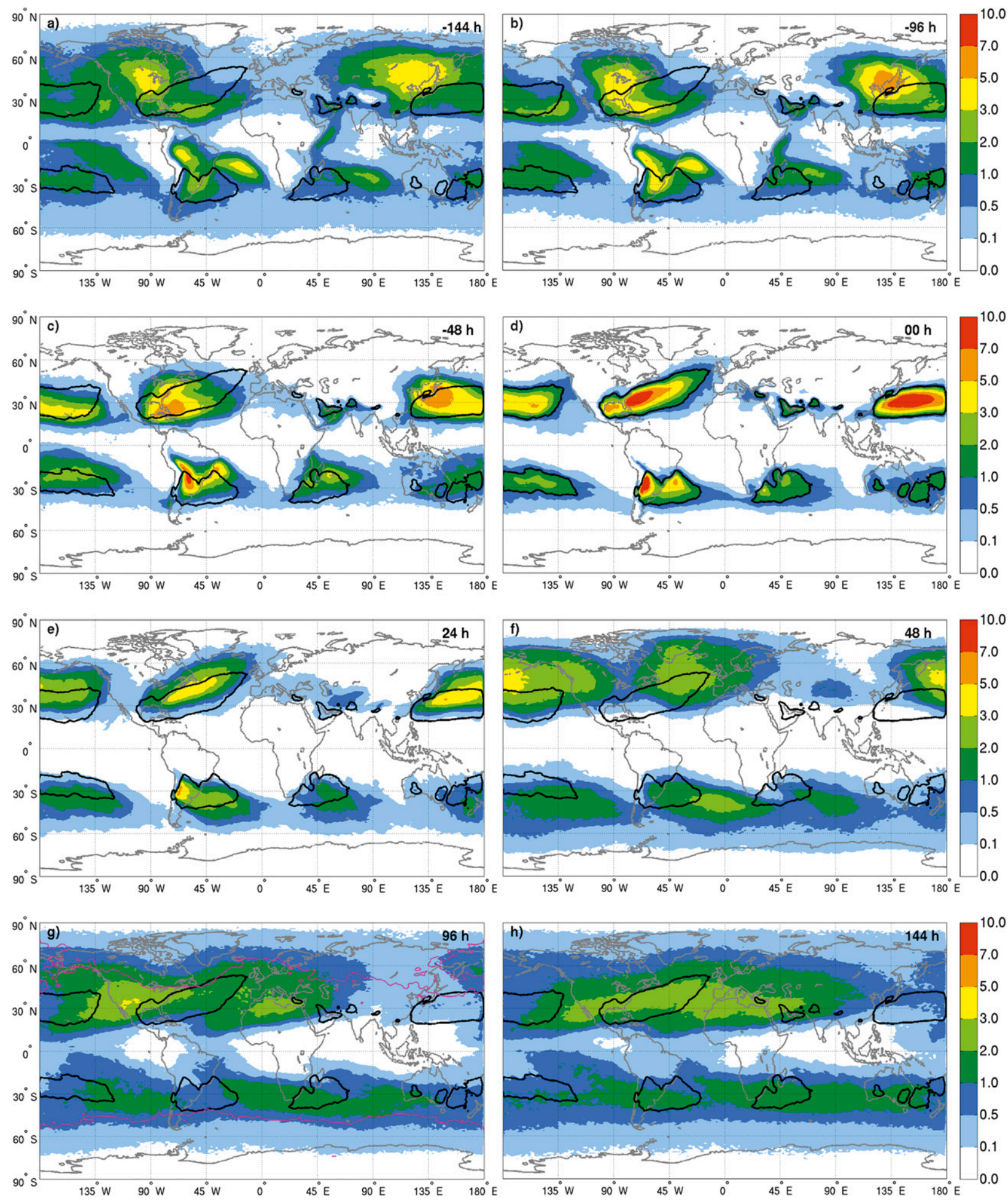

FIG. 4. Climatological frequency of WCB trajectories in DJF (a) 144, (b) 96 , and (c) $48 \mathrm{~h}$ before the start of the 2-day ascent, (d) at $t=0 \mathrm{~h}$ (WCB starting points), and (e) 24, (f) 48, (g) 96, and (h) $144 \mathrm{~h}$ after the start of the ascent. Colors represent the relative frequency (in percent) of WCB trajectories at each grid point (see text for details). The black contour in all panels represents a WCB frequency of $1 \%$ at $t=0 \mathrm{~h}$. The magenta contour at $t=96 \mathrm{~h}$ in $(\mathrm{g})$ denotes the polar regions where more than $10 \%$ of the WCB trajectories have an absolute PV value larger than 2 PVU and are therefore in the stratosphere. 

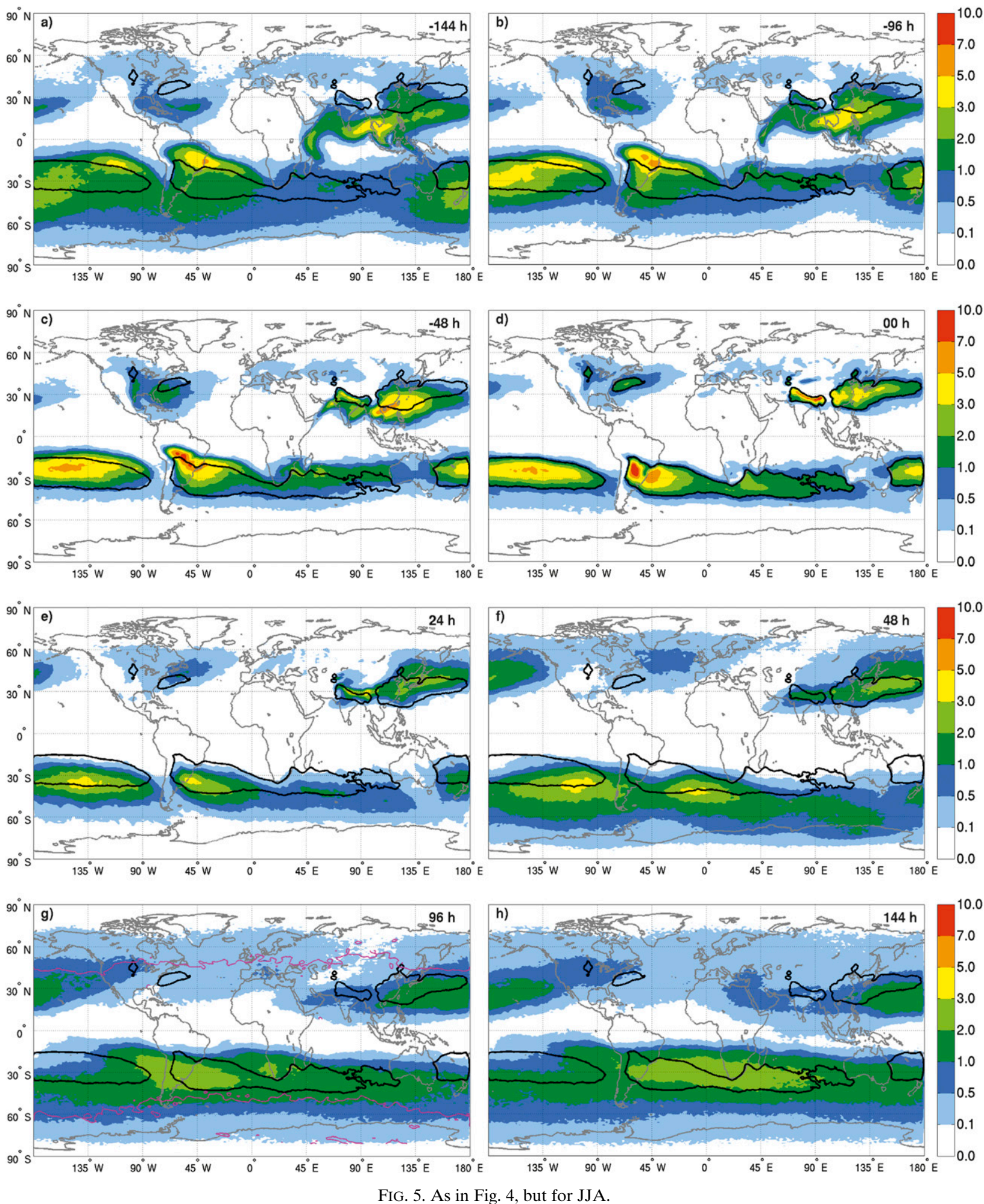

and Vera 2002; Insel et al. 2010). Insel et al. (2010) pointed out the central role of the low-level jet on the moisture transport from the Amazon basin to the central Andes. This region is also characterized throughout the year by a frequency maximum of tropical moisture export events (Knippertz et al. 2013).

Farther poleward, between about $55^{\circ} \mathrm{S}$ and the coast of Antarctica, high cyclone frequencies are found around 
the entire SH throughout the year (e.g., Sinclair 1995; Simmonds and Keay 2000; Wernli and Schwierz 2006). No WCB starting points occur in this region of intense cyclone activity, as discussed by Eckhardt et al. (2004). Because of the low temperatures less moisture can evaporate from the ocean and obviously not enough moisture is available to support the strong ascent required for WCBs. Some of these Antarctic cyclones have their origin much farther north (see Figs. 11e,f in Wernli and Schwierz 2006), and it is very likely that they are associated with WCBs during the early phase of their life cycle.

Finally, regarding the issues of atmospheric composition and aerosol-cloud interaction, it is interesting to specifically consider WCB starting points over continents (where, e.g., dust and most anthropogenic emissions occur). Although WCB starting points dominantly occur over the oceans (in particular in the NH during winter), there are significant regions over land. In the NH during summer, WCBs start over eastern North America, Europe, and in particular northern India and China. Constituents emitted in these regions can potentially affect the evolution of clouds and precipitation in WCBs starting from these areas. Of course, the composition of WCB air parcels is also affected by their pathway prior to the ascent phase, and therefore the time evolution of WCB positions is considered in the next section for times before $(t<0 \mathrm{~h})$, during $(0 \mathrm{~h}<t<$ $48 \mathrm{~h})$, and after the ascent $(t>48 \mathrm{~h})$.

\section{b. Time evolution of WCB positions}

Figures $4 \mathrm{a}-\mathrm{c}$ and $5 \mathrm{a}-\mathrm{c}$ show the WCB "source regions," that is, the WCB positions 6,4 , and 2 days prior to the start of the ascent. In DJF, at $t=-144 \mathrm{~h}$ (Fig. 4a), the trajectories are spread over large parts of the globe, including polar and tropical regions. Many of them are outside of the WCB starting points (shown by the black contours), which indicates that most WCB air parcels are transported into their region of ascent on a fairly short time scale. This is discussed in detail in Part II, which investigates the moisture origin of WCBs. Frequency maxima occur mainly over continents (North and South America, eastern Asia). In the tropics (considered here as the region between $20^{\circ} \mathrm{S}$ and $20^{\circ} \mathrm{N}$ ), there are substantial values over South America and the South Atlantic, and near-zero values over Africa, the Indian Ocean, and west of South America. In JJA (Fig. 5a), the pattern is fairly similar (compared to DJF) in the SH (with larger values in the South Pacific), but markedly different in the NH. Almost no WCB trajectories are located poleward of $60^{\circ} \mathrm{N}$, they are less abundant over the continents, and a clear maximum occurs in the Indian Ocean and western subtropical Pacific.
During the next days (Figs. 4b,c and 5b,c) the frequency distributions of course converge both from the north and the south toward the patterns of the WCB starting points at $t=0 \mathrm{~h}$. Note as an exception that many WCB trajectories starting in the South Pacific during JJA are already located in or close to this area during the previous days. The coherency of the WCB positions is clearly largest at the start of the ascent phase (Figs. 4d and 5d). This indicates that the conditions required for the triggering of WCBs (availability of low-level moisture, sufficiently strong baroclinicity, and upper-level forcing of ascent) are only fulfilled in specific geographical regions, but that the inflow and, as discussed now, ascent and outflow are more variable, leading to a confluence of WCB air parcels prior to the ascent and dispersion thereafter.

During the ascent (Figs. 4e,f and 5e,f), WCB trajectories move eastward and poleward. This movement is stronger in winter than in summer, when due to an enhanced baroclinicity stronger upper-level winds prevail. The poleward motion in winter is on average $18^{\circ}$ in both hemispheres and only $9^{\circ}(\mathrm{NH})$ and $12^{\circ}(\mathrm{SH})$ in summer. The mean eastward motion of $\mathrm{WCBs}$ is $35^{\circ}\left(39^{\circ}\right)$ in winter in the $\mathrm{NH}(\mathrm{SH})$ and $26^{\circ}\left(35^{\circ}\right)$ in summer. WCB outflow regions (i.e., their positions in the upper troposphere at the end of the ascent phase at $t=48 \mathrm{~h}$; Figs. 4f and 5f) are covering essentially the entire midlatitudes with the largest values occurring over the North and South Atlantic and Pacific, respectively. The outflow regions extend to the downstream continents (e.g., to western Europe and North America), indicating the potential to transport pollution and trace substances from one continent to another. In the winter hemispheres WCB outflows reach the polar regions, whereas in summer they hardly ever cross $70^{\circ}$ latitude. Note that at $t=48 \mathrm{~h}$ peak frequency values over the midlatitude oceans amount to more than $3 \%$, indicating that air in the upper troposphere in these areas just ascended within a WCB with a substantial likelihood of a few percent.

When they reach the upper troposphere and during the subsequent days, WCBs lose coherency as indicated by the large spread in Figs. 4g, 4h, 5g, and 5h. Their distribution becomes more and more uniform and after $t=96 \mathrm{~h}$ a shift of the WCB positions toward the equator can be observed in both hemispheres and seasons, which is very likely related to the upper-level wave activity. As shown in the example in Fig. 3, the WCB outflow typically occurs into upper-level ridges. Farther downstream they reach the western flank of the next upper-level trough where they are forced to flow toward the equator. Because of this effect we note that maxima in the WCB frequency distribution at $t=144 \mathrm{~h}$ (Figs. 4h and 5h) 
occur at similar latitudes as they did at $t=0 \mathrm{~h}$ (of course, their characteristics differ strongly in pressure, $\theta$ and $q$, as discussed in detail in the next section).

\section{Evolution of physical parameters along WCB trajectories}

The evolution of different parameters along WCB trajectories is examined for different seasons and starting regions. For this purpose we define six domains (similar to Eckhardt et al. 2004), referred to as the North Atlantic (NA), the Asian continent (AS), the North Pacific (NP), the South Atlantic (SA), the Indian Ocean (IN), and the South Pacific (SP) (see Fig. 2). In the following the temporal evolution of (a) pressure, (b) specific humidity and liquid and ice water content, (c) $\theta$, and (d) PV along WCB trajectories is investigated. Again, we distinguish among the 10-day preascent phase $(-240 \mathrm{~h}<t<0 \mathrm{~h})$, the 2-day ascent or WCB phase $(0 \mathrm{~h}<t<48 \mathrm{~h})$, and the 10-day postascent phase $(48 \mathrm{~h}<t<288 \mathrm{~h})$.

\section{a. Pressure}

In Fig. 6a the time evolution of pressure is shown for the North Atlantic WCBs during DJF. In the preascent phase the spread of the trajectories' pressure is large, some trajectories are already in the boundary layer, most of them are between 600 and $800 \mathrm{hPa}$ in the lower free troposphere, and others are in the upper troposphere, descending slowly to the boundary layer. Toward $t=0 \mathrm{~h}$ their vertical positions converge near the 950-hPa level, from where they start to rise. During the ascent phase the fairly high coherency of WCB trajectories is noticeable as well as the fast ascent. Afterward the spread in the pressure increases again. On average, the trajectories descend, but this typically dry adiabatic descent is much slower than the previous, strongly diabatic ascent. After 10 days, most of them are located in the middle troposphere, but with a very large spread from 250 to $900 \mathrm{hPa}$.

To get an impression of the pressure evolution of WCBs in different regions and seasons, Table 1 presents the averaged pressure evolution for all WCBs in six regions during DJF and JJA, respectively. Some differences are found between the two seasons. In winter, WCB trajectories start to ascend on average from about $930 \mathrm{hPa}$, whereas in summer they begin to rise from a slightly higher level (880-900 hPa). Regardless of their starting level, WCBs rise on average $625 \mathrm{hPa}$ in winter and $630 \mathrm{hPa}$ in summer. During the first $24 \mathrm{~h}$ they rise more slowly in winter than in summer and after $48 \mathrm{~h}$ they are located around $295-315 \mathrm{hPa}$ in winter while they rise up to $245-280 \mathrm{hPa}$ in summer. Large variations between the different regions are found in the $\mathrm{NH}$, especially during summer. In the North Pacific the WCB outflows reach the highest levels (on average $244 \mathrm{hPa}$, compared to $279 \mathrm{hPa}$ in the North Atlantic). In the $\mathrm{SH}$, the WCB ascent is similar in all regions even if during JJA (winter) the variability is larger than in DJF (summer). After $t=$ $96 \mathrm{~h}, \mathrm{WCB}$ trajectories descend in all regions, with the exception of the Asian continent in summer. This descent is more pronounced in winter than in summer, consistent with the steeper slope of the isentropes due to the stronger meridional temperature contrast in winter.

\section{b. Specific humidity and liquid and ice water content}

Figure $6 \mathrm{~b}$ shows the temporal evolution of specific humidity, $q$, along the North Atlantic WCBs in DJF. During the 10-day preascent phase, trajectories typically gain moisture, on average from about 2 to more than $9 \mathrm{~g} \mathrm{~kg}^{-1}$. During the ascent phase, water vapor condenses and the specific humidity decreases to nearly $0 \mathrm{~g} \mathrm{~kg}^{-1}$ at $t=48 \mathrm{~h}$. After the ascent, most WCB air parcels remain very dry, although some get significantly moister after a few days, most likely due to mixing with ambient air and moistening by convection. Figures $6 \mathrm{c}$ and $6 \mathrm{~d}$ display the evolution of the liquid and ice water content along the same WCB trajectories. Most air parcels are cloud free during the preascent phase (the median values of LWC and IWC are zero) and they reveal pronounced peaks during the ascent phase due to the condensation of water vapor and the freezing of cloud droplets. Maximum values of LWC and IWC occur at about $t=12 \mathrm{~h}$ and $t=24 \mathrm{~h}$, respectively. These peaks during the ascent show the relevance of WCBs as midlatitude cloud systems. In the postascent phase no liquid water is contained in the WCBs for several days, but low values of IWC are present in some WCB air parcels during the days after the ascent.

We now focus in more detail on the ascent phase and consider the evolution of $q$, LWC, and IWC during the ascent as a function of pressure. Since the trajectories do not rise uniformly with time, complementary information is obtained by regarding the evolution of the parameters as a function of pressure instead of time. Figure 7a illustrates the evolution of $q$ with respect to pressure for the North Atlantic WCBs in DJF. The percentiles (gray areas) are only shown if at least $40 \%$ of the trajectories are available at this pressure level. For the levels $850,700,550,400$, and $300 \mathrm{hPa}$, detailed quantitative information is given for several parameters and WCB regions for the seasons DJF and JJA in Table 2a.

Low-level moisture values in WCB trajectories are larger in summer than in winter (see, e.g., the values at $850 \mathrm{hPa}$ in Table 2a), due to higher temperatures in the 

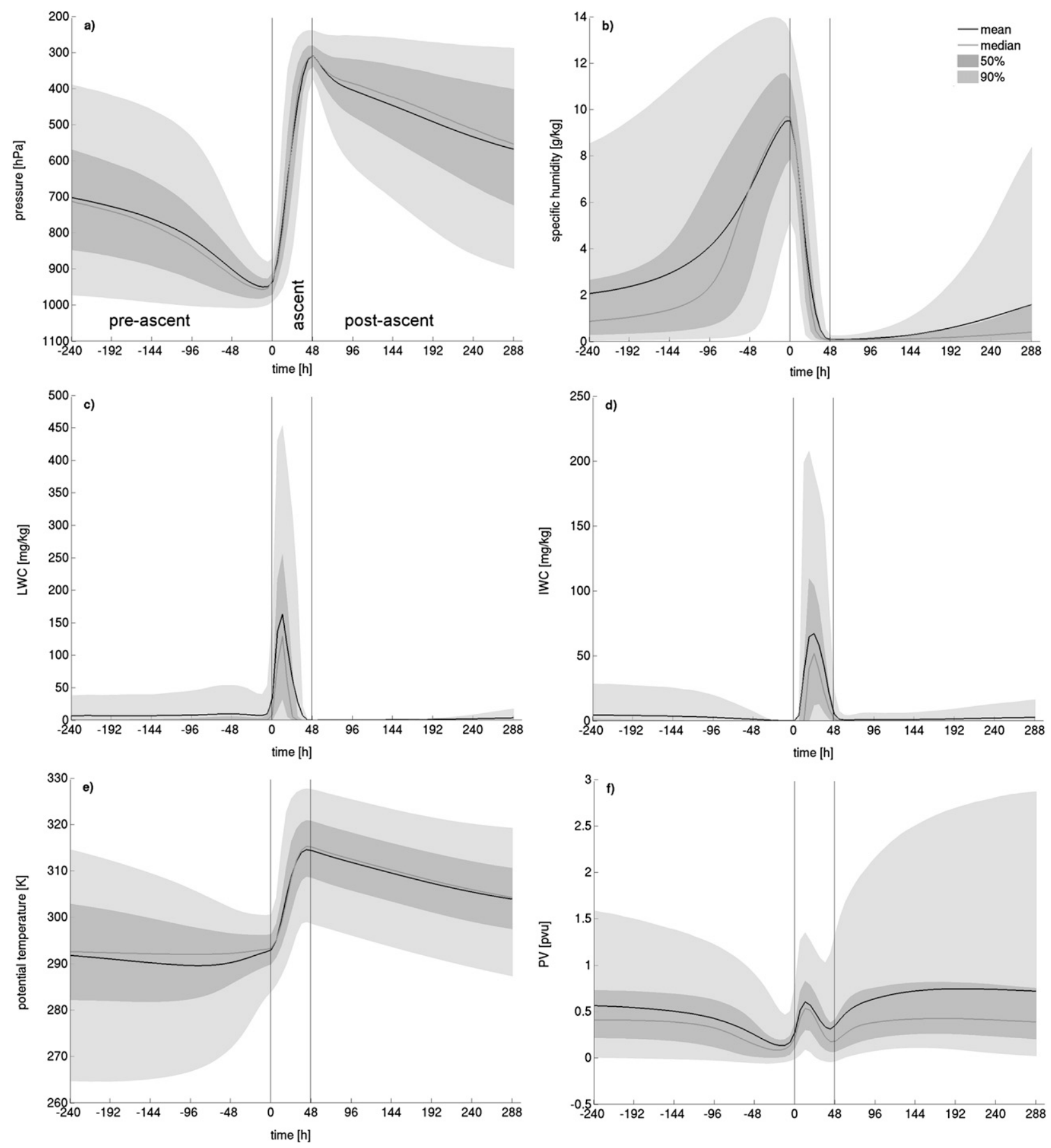

FIG. 6. Temporal evolution of (a) pressure $p$ (in hPa), (b) specific humidity $q$ (in $\mathrm{g} \mathrm{kg}^{-1}$ ), (c) liquid and (d) ice water content (in $\mathrm{mg} \mathrm{kg}^{-1}$ ), (e) potential temperature $\theta$ (in K), and (f) PV (in PVU) along WCB trajectories starting in the North Atlantic during DJF. The preascent, WCB, and postascent phases are indicated by vertical lines. Black lines show the mean values over all trajectories, gray lines the median, and the dark and light gray areas represent the interquartile range (25th-75th percentiles) and the range between the 5 th and 95 th percentiles, respectively.

WCB inflow regions. In summer, the values of $q$ in WCBs at $850 \mathrm{hPa}$ are slightly larger in the NH than in the SH (Table $2 \mathrm{a}$ ) and vice versa in winter, indicating a more pronounced seasonal cycle of low tropospheric humidity over the NH oceans. For the winter WCBs in the North Atlantic there is a fairly linear decrease of $q$ with decreasing pressure, from about $8 \mathrm{~g} \mathrm{~kg}^{-1}$ at $850 \mathrm{hPa}$ to $0.1 \mathrm{~g} \mathrm{~kg}^{-1}$ at $300 \mathrm{hPa}$ (Fig. 7a and Table 2a). 
TABLE 1. Mean temporal evolution of pressure (in $\mathrm{hPa}$ ) along WCB trajectories in DJF/JJA starting from six different regions (see Fig. 2). The WCB ascent occurs from $t=0 \mathrm{~h}$ to $t=48 \mathrm{~h}$.

\begin{tabular}{rcccccc}
\hline \hline Time $(\mathrm{h})$ & NA & AS & NP & SA & IN & SP \\
\hline-144 & $762 / 868$ & $773 / 891$ & $724 / 898$ & $834 / 771$ & $856 / 754$ & $864 / 757$ \\
-96 & $817 / 897$ & $834 / 906$ & $785 / 913$ & $867 / 830$ & $897 / 824$ & $900 / 828$ \\
-48 & $903 / 924$ & $896 / 912$ & $891 / 923$ & $901 / 898$ & $930 / 912$ & $929 / 910$ \\
-24 & $941 / 933$ & $922 / 912$ & $939 / 923$ & $915 / 927$ & $936 / 944$ & $935 / 939$ \\
00 & $935 / 906$ & $921 / 876$ & $939 / 879$ & $900 / 924$ & $904 / 934$ & $902 / 926$ \\
24 & $533 / 494$ & $530 / 413$ & $533 / 432$ & $444 / 534$ & $455 / 546$ & $440 / 487$ \\
48 & $310 / 279$ & $298 / 240$ & $313 / 244$ & $271 / 298$ & $271 / 309$ & $268 / 296$ \\
96 & $406 / 317$ & $441 / 242$ & $427 / 259$ & $327 / 427$ & $323 / 439$ & $314 / 395$ \\
144 & $449 / 349$ & $496 / 247$ & $465 / 274$ & $360 / 479$ & $350 / 488$ & $339 / 440$ \\
\hline
\end{tabular}

This decrease of water vapor along the ascending WCB trajectories is due to condensation (primarily in the early phase) and depositional growth of ice (in the mixed phase cloud regime). Accordingly, as $q$ is decreasing at lower levels, we observe an increase of the LWC, which reaches maximum values at about $750 \mathrm{hPa}$ in winter, independently of the region (example shown in Fig. $7 \mathrm{~b}$ for the North Atlantic). In summer, due to warmer temperatures, peak values of LWC are reached at $650 \mathrm{hPa}$ (not shown). As for $q$, averaged peak values of LWC in WCBs are largest in summer in all the considered regions [ $>300 \mathrm{mg} \mathrm{kg}^{-1}$ (see Table $2 \mathrm{c}$ ) compared to $>250 \mathrm{mg} \mathrm{kg}^{-1}$ in winter].

As the WCB air parcels continue to rise, liquid cloud water freezes and water vapor is deposited onto ice crystals. Hence, for instance, for winter WCBs in the North Atlantic (Figs. 7b,c) we observe a decrease in LWC and an increase in IWC between 750 and $500 \mathrm{hPa}$. As for the LWC, the level of maximum IWC is higher during summer $(450 \mathrm{hPa}$; not shown), similar in all regions. Mean peak values of IWC are about $150 \mathrm{mg} \mathrm{kg}^{-1}$ in summer and $125 \mathrm{mg} \mathrm{kg}^{-1}$ in winter. Because of the continuous formation of precipitation, the total water content along the WCB is steadily decreasing. In the outflow of winter WCBs in the North Atlantic (i.e., at $300 \mathrm{hPa}$ ), the LWC is almost zero for all WCB trajectories (Fig. 7b) whereas the mean IWC amounts to about $30 \mathrm{mg} \mathrm{kg}^{-1}$ (Fig. 7c and Table 2d) with fairly large variations. This clearly indicates the ability of WCBs to produce cirrus clouds in their upper tropospheric outflow regions. As shown in Fig. 6d, the average IWC value is rapidly decreasing after $t=48 \mathrm{~h}$. However, some WCB trajectories are characterized by fairly persistent cirrus clouds (note the light gray shading). It would be interesting to investigate the upper-level flow pattern that goes along with the existence of persistent cirrus in the WCB outflow, compared to the more typical situation of a slow descent and concomitant vanishing of the cloud.

\section{c. Potential temperature}

The latent heat release associated with the phase changes during the WCB ascent (condensation, vapor deposition, freezing) leads to a strong increase of the WCBs' potential temperature during the ascent (see Fig. 6e). For instance, for winter WCBs in the North Atlantic the mean net heating amounts to about $20 \mathrm{~K}$ between 850 and $300 \mathrm{hPa}$ (see Fig. 7d). This net heating varies with season and WCB region and can reach almost $40 \mathrm{~K}$ (Table $2 \mathrm{~b}$ ). Note that the net heating values are potentially also influenced by turbulent heat fluxes in the marine boundary layer and radiative heating. However, an estimate of the latent heating associated with the diagnosed loss of $q$ due to condensation reveals that latent heating plays the dominant role. In the low troposphere (at $850 \mathrm{hPa}$ ) the range of averaged $\theta$ values over the different regions in the WCB inflow is $293-298 \mathrm{~K}$ in winter and $302-308 \mathrm{~K}$ in summer. In the WCB outflow at $300 \mathrm{hPa}$, the air parcels reach mean values of 313-321 $\mathrm{K}$ in winter and 333-346K in summer. The larger variability in summer is mainly due to the high $\theta$ values in the outflow of Asian and North Pacific WCBs. This clearly shows that the cross-isentropic ascent of WCBs can reach at least to $315 \mathrm{~K}$ in winter and $335 \mathrm{~K}$ in summer, where they potentially modify the synoptic-scale flow evolution. These potential temperature changes are larger than those reported by Eckhardt et al. (2004), mainly due to the separate consideration of the seasons. The potential of WCBs to modify the upperlevel flow becomes evident when considering the PV evolution along the cross-isentropic ascent, as done in the next subsection.

\section{d. Potential vorticity}

The PV of an air parcel can only be changed by diabatic or frictional processes and is conserved along adiabatic flows. Figure $6 \mathrm{f}$ shows the evolution of PV along WCBs in the North Atlantic during winter for the preascent, ascent, and postascent phase. Before the ascent we observe on average fairly low, typically tropospheric PV values, followed by a steep PV increase during the first part of the ascent and a decrease in the second part. In the postascent phase some trajectories reach more than 2 PVU, indicating a crossing of the tropopause into the stratosphere. The latter process has been reported in earlier trajectory studies (Stohl 2001; Wernli and Bourqui 2002; Eckhardt et al. 2004). It is likely a combined consequence of radiative heating gradients associated with the pronounced humidity contrasts in the surrounding of the WCB outflow and turbulent mixing near the jet-issues that are not further investigated in this study (except that the magenta contours in 

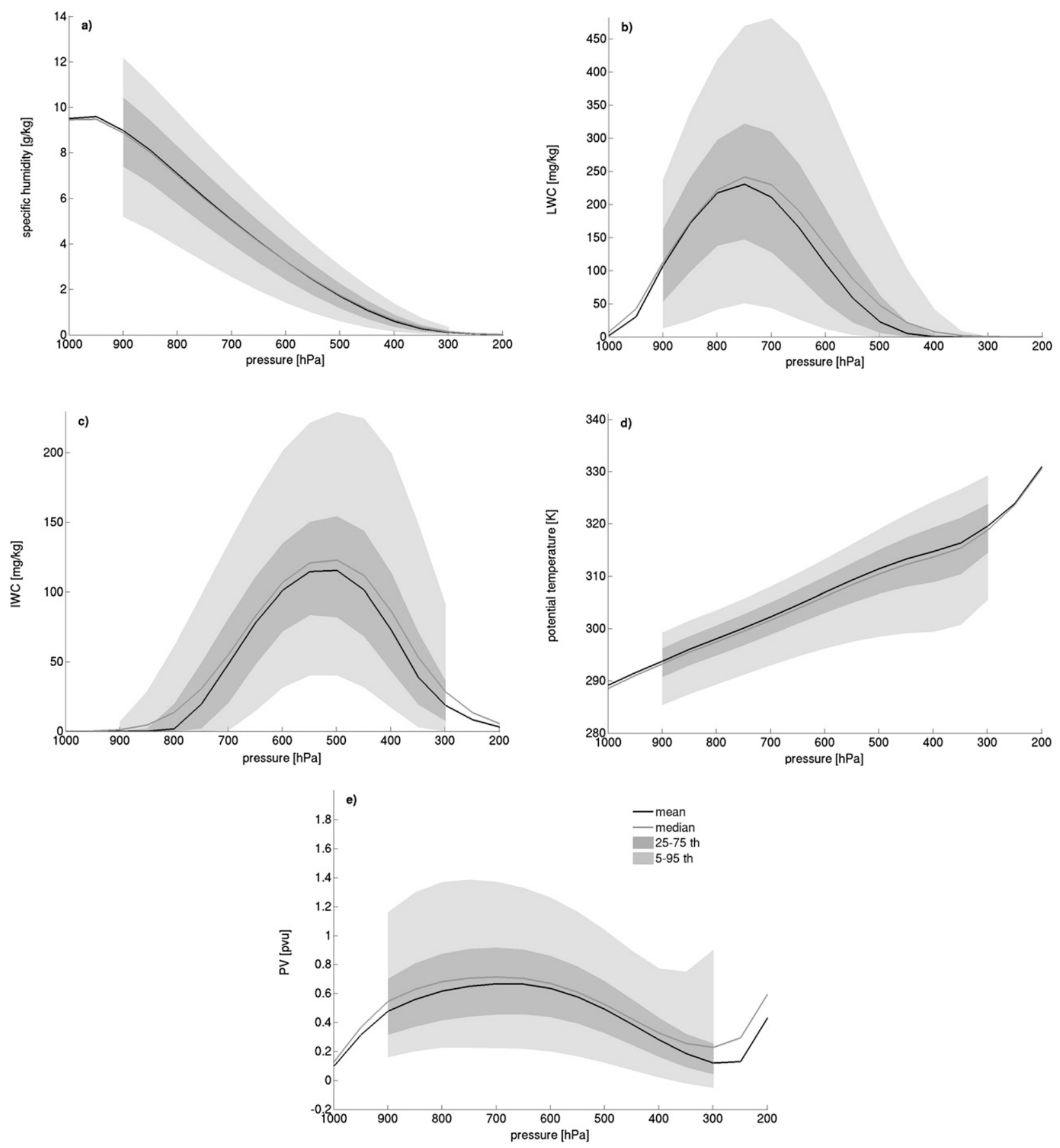

FIG. 7. Evolution of various parameters for the North Atlantic DJF during the ascent phase of WCBs as a function of pressure for the same WCBs as shown in Fig. 6. The parameters shown are (a) $q$, (b) LWC, (c) IWC, (d) $\theta$, and (e) PV. Units, line conventions and shadings are as in Fig. 6.

Figs. $4 \mathrm{~g}$ and $5 \mathrm{~g}$ indicate that at $t=96 \mathrm{~h}$ the fraction of WCB trajectories that entered the stratosphere is largest poleward of $60^{\circ}$ ). However, the PV evolution during the ascent, mainly related to latent heating processes and documented previously by, for example, Wernli and Davies (1997) and Eckhardt et al. (2004), will be analyzed in greater detail in the following. Key questions that are addressed are whether the PV evolution during the ascent depends on the latitude of the ascent and/or on the initial moisture value in the WCBs. In other words, we test the hypothesis that a larger moisture content (leading to stronger net latent heating) also leads to a more 
TABLE 2. Quantitative information (arithmetic means) of various parameters at different pressure levels along WCBs starting in six different regions for DJF/JJA: (a) specific humidity $q\left(\mathrm{~g} \mathrm{~kg}^{-1}\right)$, (b) potential temperature $\theta(\mathrm{K})$, (c) liquid water content ( $\mathrm{LWC}^{\mathrm{mg} \mathrm{kg}}{ }^{-1}$ ), (d) ice water content (IWC; $\mathrm{mg} \mathrm{kg}^{-1}$ ), and (e) PV (PVU).

\begin{tabular}{|c|c|c|c|c|c|c|}
\hline Region & NA & AS & NP & SA & IN & SP \\
\hline (a) & \multicolumn{6}{|c|}{$q\left(\mathrm{~g} \mathrm{~kg}^{-1}\right)$} \\
\hline 850 & $8.0 / 11.3$ & $6.8 / 14.3$ & $8.2 / 13.5$ & $11.4 / 8.1$ & $11.7 / 6.9$ & $11.5 / 8.9$ \\
\hline 700 & $5.0 / 7.8$ & $4.8 / 11.3$ & $5.9 / 9.9$ & $8.1 / 5.2$ & $8.3 / 4.2$ & $8.2 / 5.8$ \\
\hline 550 & $2.4 / 4.4$ & $2.3 / 7.3$ & $2.6 / 6.1$ & $4.6 / 2.5$ & $4.8 / 1.9$ & $4.8 / 3.0$ \\
\hline 400 & $0.7 / 1.6$ & $0.6 / 3.2$ & $0.7 / 2.6$ & $1.7 / 0.7$ & $1.9 / 0.5$ & $1.8 / 0.9$ \\
\hline 300 & $0.1 / 0.5$ & $0.1 / 1.3$ & $0.2 / 0.9$ & $0.5 / 0.2$ & $0.6 / 0.1$ & $0.6 / 0.2$ \\
\hline (b) & \multicolumn{6}{|c|}{$\theta(\mathrm{K})$} \\
\hline 850 & $296 / 302$ & $298 / 308$ & $296 / 304$ & $303 / 296$ & $302 / 293$ & $302 / 297$ \\
\hline 700 & $302 / 309$ & $302 / 316$ & $302 / 313$ & $310 / 302$ & $310 / 299$ & $310 / 304$ \\
\hline 550 & $308 / 318$ & $308 / 326$ & $309 / 323$ & $318 / 309$ & $319 / 305$ & $319 / 311$ \\
\hline 400 & $314 / 327$ & $313 / 337$ & $314 / 334$ & $327 / 314$ & $328 / 309$ & $328 / 317$ \\
\hline 300 & $319 / 333$ & $316 / 346$ & $321 / 342$ & $333 / 318$ & $336 / 313$ & $335 / 321$ \\
\hline (c) & \multicolumn{6}{|c|}{ LWC ( $\left.\mathrm{mg} \mathrm{kg}^{-1}\right)$} \\
\hline 850 & $174 / 137$ & $71 / 111$ & $192 / 153$ & $144 / 156$ & $177 / 171$ & $168 / 190$ \\
\hline 700 & $229 / 278$ & $151 / 303$ & $256 / 298$ & $303 / 227$ & $299 / 185$ & $302 / 270$ \\
\hline 550 & $87 / 191$ & $69 / 321$ & $108 / 276$ & $226 / 93$ & $227 / 55$ & $230 / 131$ \\
\hline 400 & $7 / 31$ & $7 / 111$ & $12 / 63$ & $57 / 11$ & $58 / 4$ & $50 / 19$ \\
\hline 300 & $0.4 / 3$ & $0.6 / 21$ & $1.0 / 7$ & $12 / 0.9$ & $11 / 0.3$ & $7 / 2$ \\
\hline (d) & \multicolumn{6}{|c|}{ IWC ( $\left.\mathrm{mg} \mathrm{kg}^{-1}\right)$} \\
\hline 850 & $5 / 0$ & $4 / 0$ & $6 / 0$ & $1 / 4$ & $1 / 6$ & $1 / 3$ \\
\hline 700 & $55 / 21$ & $51 / 14$ & $58 / 11$ & $29 / 52$ & $27 / 65$ & $25 / 49$ \\
\hline 550 & $121 / 105$ & $106 / 75$ & $126 / 81$ & $119 / 119$ & $110 / 111$ & $110 / 126$ \\
\hline 400 & $86 / 126$ & $78 / 147$ & $92 / 144$ & $152 / 93$ & $145 / 68$ & $142 / 107$ \\
\hline 300 & $28 / 64$ & $27 / 124$ & $33 / 101$ & $95 / 36$ & $94 / 21$ & $84 / 38$ \\
\hline (e) & \multicolumn{6}{|c|}{ PV (PVU) } \\
\hline 850 & $0.63 / 0.79$ & $0.32 / 0.51$ & $0.61 / 0.79$ & $-0.61 /-0.61$ & $-0.74 /-0.62$ & $-0.66 /-0.55$ \\
\hline 700 & $0.71 / 1.00$ & $0.47 / 0.73$ & $0.69 / 1.01$ & $-0.76 /-0.73$ & $-0.87 /-0.71$ & $-0.78 /-0.62$ \\
\hline 550 & $0.61 / 1.00$ & $0.42 / 0.75$ & $0.57 / 1.03$ & $-0.71 /-0.63$ & $-0.84 /-0.57$ & $-0.76 /-0.53$ \\
\hline 400 & $0.33 / 0.68$ & $0.19 / 0.59$ & $0.30 / 0.81$ & $-0.44 /-0.32$ & $-0.55 /-0.27$ & $-0.49 /-0.27$ \\
\hline 300 & $0.23 / 0.42$ & $0.13 / 0.35$ & $0.24 / 0.44$ & $-0.25 /-0.22$ & $-0.31 /-0.21$ & $-0.27 /-0.21$ \\
\hline
\end{tabular}

pronounced increase and subsequent decrease of PV. Clearly, since the diabatic material PV changes are proportional to the gradient of the latent heating (and not to the latent heating itself) and to the absolute vorticity [cf. Eq. (2)], addressing this hypothesis requires a detailed analysis as performed in the next section.

In Fig. 7e the PV evolution during the ascent of winter WCBs in the North Atlantic is visualized as a function of pressure. At $850 \mathrm{hPa} \mathrm{PV}$ values are close to 0.6 PVU and they increase toward higher levels. The averaged maximum value of $0.71 \mathrm{PVU}$ is reached at $700 \mathrm{hPa}$. However, variability is large and at $700 \mathrm{hPa}$ the $5 \%-95 \%$ percentile range extends from 0.23 to 1.37 PVU. At higher levels, PV typically starts to decrease and at $300 \mathrm{hPa}$ the mean PV value amounts to 0.23 PVU. This climatological evolution of PV confirms earlier results, for example, from the case study by Wernli and Davies (1997), who showed that the typical evolution of PV in a WCB is characterized by low $\mathrm{PV}$ values in the lower troposphere, followed by an increase and a decrease to again low values in the WCB outflow. Also it confirms the similar PV evolution along a WCB in an idealized moist baroclinic wave experiment by Schemm et al. (2013), who also noted a slightly reduced PV value in the outflow compared to the inflow.

A qualitatively similar PV evolution along WCB trajectories is found in all regions and for all seasons, of course with negative PV values in the SH. However, during summer both the initial PV values and the peak values are slightly higher (see Table 2e). In the $\mathrm{NH}(\mathrm{SH})$ regions, the largest mean peak $\mathrm{PV}$ values in winter are $0.71 \mathrm{PVU}(-0.73 \mathrm{PVU})$ and occur at $700 \mathrm{hPa}$, whereas in summer they amount to $1.03 \mathrm{PVU}(-0.87 \mathrm{PVU})$ at an altitude of $550 \mathrm{hPa}(700 \mathrm{hPa})$. At $300 \mathrm{hPa}$, the largest mean PV values amount to $0.24 \mathrm{PVU}(-0.22 \mathrm{PVU})$ in winter and to $0.44 \mathrm{PVU}(-0.31 \mathrm{PVU})$ in summer. The 

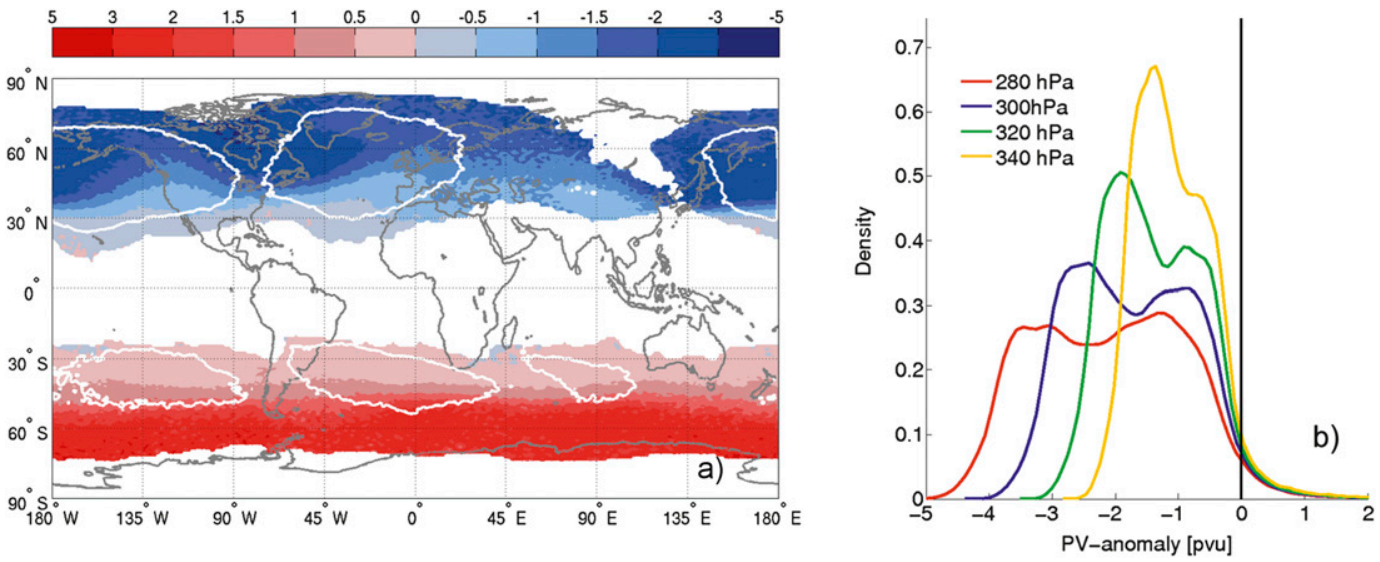

FIG. 8. Quantification of PV anomalies in the WCB outflow in DJF. (a) Distribution of PV anomalies averaged for all WCB trajectories located at $t=48 \mathrm{~h}$ between 340 and $280 \mathrm{hPa}$. White contours denote areas where the relative frequency of WCB trajectories at $t=48 \mathrm{~h}$ exceeds $1 \%$. (b) Probability density functions of the PV anomalies of WCBs in the $\mathrm{NH}$ at $340,320,300$, and $280 \mathrm{hPa}$, respectively.

contrast between the different regions is remarkably small.

To quantify how anomalous these low PV values in the upper-tropospheric WCB outflow regions are, we calculate for every WCB trajectory the difference between the climatological PV value at the position of the trajectory at $t=48 \mathrm{~h}$ and the actual PV value of the trajectory. This analysis is performed separately for WCB trajectories that, at $t=48 \mathrm{~h}$, are located close to $340,320,300$, and $280 \mathrm{hPa}$, respectively. The climatological fields were taken as monthly mean PV values on the respective pressure surfaces for the entire 32-yr period. Figure 8 shows both the geographical distribution of the temporally and vertically averaged PV anomalies and the probability density functions (PDFs, only for the NH) at the four pressure levels for DJF. The geographical distribution has been obtained by averaging the PV anomaly values of all WCB trajectories that are located in the respective grid box at $t=48 \mathrm{~h}$. The anomalies are substantial and reach values up to -3 PVU in the $\mathrm{NH}$ and +3 PVU in the $\mathrm{SH}$, indicating that the WCB outflow occurs at altitudes that are, on average, in the lower stratosphere. Some regions with very high frequencies of WCB outflows (e.g., over the eastern North Pacific and North Atlantic) are regions with a climatological ridge (i.e., their climatological PV is comparatively low). Therefore the same PV in the outflow of WCBs produces a weaker anomaly in these regions compared to the climatological trough regions (e.g., over Newfoundland), as shown in Fig. 8a. The PDFs at the four pressure levels (Fig. 8b) nicely illustrate that the amplitude of the anomalies is fairly weak for WCBs that only ascend up to $340 \mathrm{hPa}$ ( $<2$ PVU) and much larger for $\mathrm{WCB}$ trajectories that rise to
$280 \mathrm{hPa}$ (up to $4 \mathrm{PVU}$ ). These are very significant anomaly values, which quantify the overall relevance of WCBs for producing upper-level anticyclonic circulations that can further influence the downstream flow evolution.

\section{Detailed analysis of cloud diabatic PV modification}

\section{a. Spatial distribution of high low-level PV}

In the previous section we have illustrated that along the ascending WCB trajectories, due to diabatic processes, a positive PV anomaly forms at low levels and a negative anomaly in the WCB outflow regions. Here we first investigate if WCBs that produce particularly intense positive $\mathrm{PV}$ anomalies in the lower troposphere occur in preferred regions. To this end the $5 \%$ of trajectories are considered reaching the largest $\mathrm{PV}$ values between the surface and $500 \mathrm{hPa}$, separately for the two hemispheres and the winter and summer seasons. In the $\mathrm{NH}$ this 5\% threshold amounts to 1.37 PVU in winter and 1.81 PVU in summer. The values in the $\mathrm{SH}$ are -1.28 and $-1.51 \mathrm{PVU}$, respectively. Trajectories that have their maximum PV values at $t=0 \mathrm{~h}$ are not considered, since this anomalous PV might be of frictional origin. The selected WCB trajectories with high low-level PV (referred to as HLPV trajectories) typically reach their peak values at $t=6 \mathrm{~h}$ or $t=12 \mathrm{~h}$ (not shown). (As a caveat it is noted that we cannot exclude that some of these peak values are influenced by frictional processes, but since the following analysis of PV changes due to latent heating leads to consistent results, frictional effects should be of minor importance.) About three-quarters of these trajectories exceed the threshold only at one 6-hourly time step, 


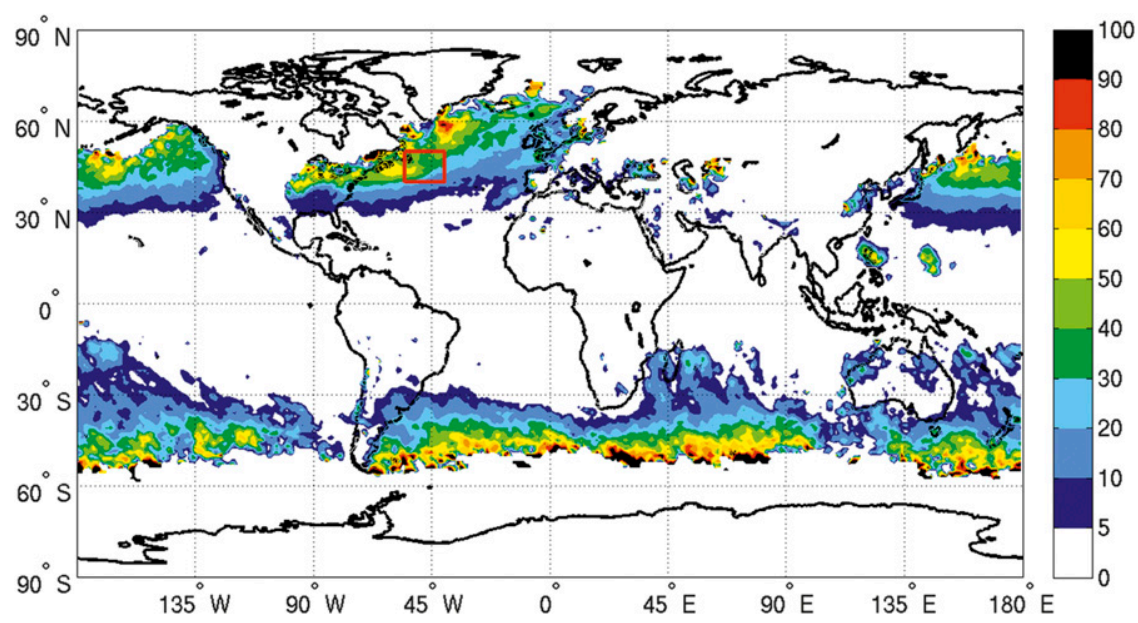

FIG. 9. Spatial distribution at $t=0 \mathrm{~h}$ of the percentage of those WCB trajectories at each grid point in DJF that exceed the HLPV threshold at some time along the trajectory, which amounts to $1.37 \mathrm{PVU}$ in the $\mathrm{NH}$ and $-1.51 \mathrm{PVU}$ in the $\mathrm{SH}$. The red box denotes the region between $55^{\circ}$ and $40^{\circ} \mathrm{W}$ and $40^{\circ}$ and $50^{\circ} \mathrm{N}$.

indicating the ephemeral character of the diabatic PV production. In winter, for less than $5 \%$ of the selected trajectories the positive PV anomaly is so strong that the threshold is exceeded for $18 \mathrm{~h}$ or longer. In summer, this occurs more often, in about $10 \%$ of the cases. It would be interesting to further investigate this subset of WCBs, in particular the impact of their intense and fairly long-lived positive $\mathrm{PV}$ anomalies on the evolution of the cyclone.

It is interesting to consider the spatial distribution of the HLPV trajectories. Figure 9 shows at every grid point the percentage of the WCB trajectories at $t=0 \mathrm{~h}$ that belong to the HLPV category. A strong meridional gradient is evident. Trajectories starting their ascent nearer to the poles are more likely to develop HLPV (values larger than $50 \%$ ) whereas trajectories closer to the equator very rarely exceed the HLPV threshold. This indicates that the latitude of the onset of the diabatic heating plays an important role in determining the initial increase in PV. WCB trajectories that start closer to the equator are likely associated with higher specific humidity values (which is potentially favorable for a strong diabatic PV modification), but they are also characterized by reduced planetary vorticity. Given the overall meridional gradient shown in Fig. 9 the latter is obviously a very important factor. Intense latent heating at low latitudes does not lead to a prominent material change of PV due to the typically low value of absolute vorticity [cf. Eq. (2)]. A similar result was found by Martius and Wernli (2012), who showed that diabatic effects in the subtropics have a negligible effect on the $\mathrm{PV}$ distribution associated with upper-tropospheric jet streams over North Africa.

\section{b. Formation mechanism for high low-level PV}

However, the latitudinal variation of planetary vorticity is not the only factor affecting the diabatic PV modification in WCBs, as indicated by the large spatial variability in the North Atlantic, North Pacific, and in the SH in the amount of WCBs that develop HLPV. To further investigate this variability, we focus on WCB trajectories in winter starting in a subregion of the North Atlantic (see red box in Fig. 9). They have similar starting conditions in terms of, for instance, latitude, planetary vorticity, and sea surface temperature, and it is therefore revealing to identify differences between the trajectories that exceed the HLPV threshold and those that do not. For this region the HLPV threshold (top 5\% of maximum low-level PV values) amounts to 1.52 PVU. Considering separately the averaged evolution of specific humidity and potential temperature for the two categories reveals hardly any differences, indicating that, on average, the initial humidity and temperature are not the key factors determining the subsequent PV evolution.

As a next step, we trace the vorticity (absolute and relative) and the vertical gradient of the diabatic heating rate along the WCB trajectories starting from the red box region during the winter season (DJF) 2002. Figure 10 shows the mean, the interquartile range (25th and 75 th percentile), and the 5\%-95\% interpercentile range for the HLPV category in red and for the non-HLPV trajectories in gray as a function of pressure. Again, the percentiles are shown only if at least $40 \%$ of the data are available at the pressure level. Between 900 and $750 \mathrm{hPa}$ the mean vertical gradient of the diabatic heating is slightly larger in magnitude (i.e., more negative) for the 
a)

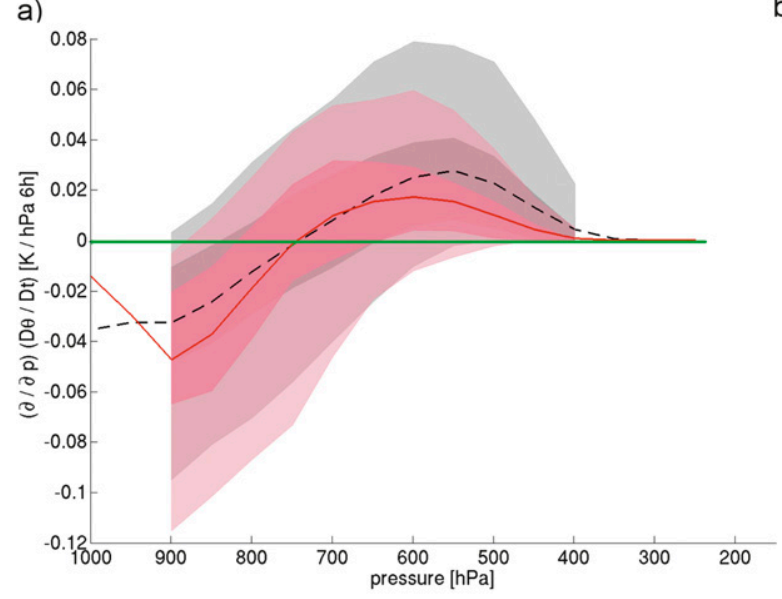

b)

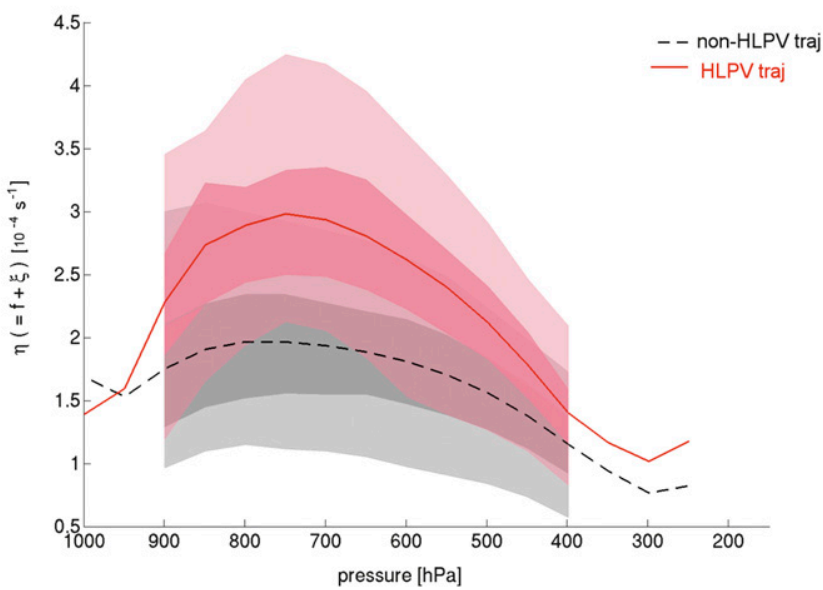

FIG. 10. Comparison of the evolution of (a) the vertical gradient of diabatic heating and (b) absolute vorticity as a function of pressure during the ascent phase of WCBs starting from the region in the red box (see Fig. 9) in DJF 2002. Mean, interquartile range, and the 5\%95\% interpercentile range are shown in red for HLPV trajectories and in gray for non-HLPV trajectories.

HLPV trajectories (Fig. 10a). However, the differences are not significant since the interquartile ranges of the HLPV and non-HLPV trajectories are strongly overlapping. In contrast, already at $900 \mathrm{hPa}$ the mean absolute vorticity of the HLPV trajectories is above the interquartile range of the non-HLPV trajectories, and at $700 \mathrm{hPa}$ the mean value of the former category is even higher than the 95th percentile of the latter (Fig. 10b). At this level $(900 \mathrm{hPa})$, the mean PV values of the HLPV trajectories are also above the interquartile range of the non-HLPV trajectories (not shown) so that the trajectories in the two categories do not start with similar initial conditions in terms of PV. We learn from this analysis that HLPV and non-HLPV WCB trajectories starting from the same region on average do not differ in the vertical gradient of latent heating they experience during their early ascent, but they differ in terms of their initial PV (and absolute vorticity values). WCB trajectories with higher $\mathrm{PV}$ at the start of the ascent are more likely to develop very high peak values along the ascent. The reason for this is that high PV typically implies high absolute vorticity, which (for a given vertical gradient of latent heating) leads to a larger material change of PV.

Finally, we restrict our analysis to WCB trajectories starting with the same initial PV value (the subset of the trajectories investigated above for which $\mathrm{PV}$ at $t=0 \mathrm{~h}$ is within the $45 \%-55 \%$ percentile range) and separate this subset again in the categories HLPV and non-HLPV. For the two categories, we investigate the averaged time evolution during the first phase of the ascent of PV, the vertical gradient of the diabatic heating, and vorticity (relative, absolute, and planetary). Figure 11a shows the PV evolution; the values are very similar at $t=0 \mathrm{~h}$ per construction. During the next $6 \mathrm{~h}$ a PV increase is observed for both categories, which is, however, much stronger for the HLPV trajectories. Their median value exceeds the 75th percentile of the non-HLPV trajectories at $t=6 \mathrm{~h}$. At $t=12 \mathrm{~h}$ the differences between the two categories are even more pronounced (median values of 1.55 and $0.70 \mathrm{PVU}$, respectively). The differences are still substantial at $t=18 \mathrm{~h}$ and decrease thereafter, when mean PV values decrease along both categories of WCB trajectories. At $t=0 \mathrm{~h}$ the vertical gradient of the diabatic heating (Fig. 11b) has similar values for both categories and the same is true for absolute vorticity $\eta$, which is the sum of relative vorticity $\zeta$ (Fig. 11c) and the Coriolis parameter (Fig. 11d). Six hours later we observe that HLPV trajectories experience a stronger vertical heating gradient (median values are more than twice as large as for non-HLPV trajectories). Also their absolute vorticity is slightly larger, but with a very large variance. We can therefore infer that the intensity of the initial PV modification is mainly determined by the vertical gradient of the diabatic heating (for trajectories starting with very similar PV values). After $12 \mathrm{~h}$, the mean vertical heating gradient is similar for the two categories of trajectories (Fig. 11b), although even larger differences in PV are observed. At that time the higher values of absolute vorticity (Fig. 11c) cause a larger PV increase despite similar heating gradients. Therefore the different increase in PV between $t=6 \mathrm{~h}$ and $t=12 \mathrm{~h}$ is mainly due to the difference in absolute vorticity. We finally note that this difference is mostly due to the relative vorticity $\zeta$, which increases from vortex stretching due to the upward increase in latent heating. The Coriolis parameter $f$ increases steadily along the ascent since WCBs are moving poleward. It is slightly larger for the HLPV trajectories, but the medians of the two categories differ 

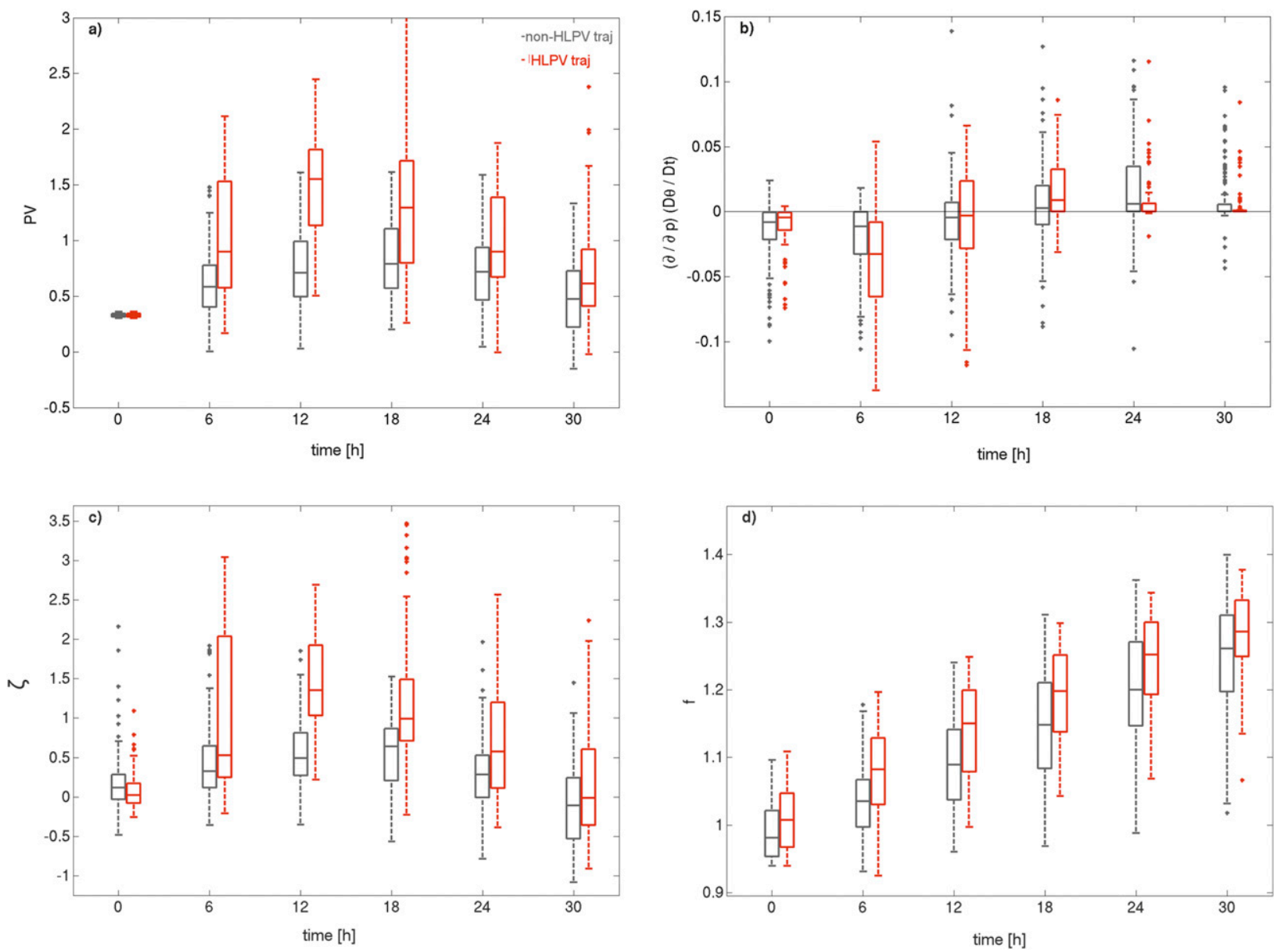

FIG. 11. Box plot of the temporal evolution of (a) PV, (b) the vertical gradient of latent heating, (c) relative vorticity, and (d) the Coriolis parameter for trajectories starting in DJF 2002 in the red box shown in Fig. 9 with similar initial PV values. Values for HLPV trajectories are shown in red, and for non-HLPV trajectories in gray.

much less for $f$ than for $\zeta\left(0.14 \times 10^{-4} \mathrm{~s}^{-1}\right.$ versus $0.86 \times$ $10^{-4} \mathrm{~s}^{-1}$ at $t=12 \mathrm{~h}$ ). To summarize, this detailed analysis has shown that the vertical gradient of the diabatic heating is preferentially associated with the production of high PV in the initial phase of the WCB ascent. However, once PV is diabatically enhanced, the positive feedback mechanism (higher PV on average goes along with higher relative vorticity) becomes important, leading to a stronger PV increase along HLPV trajectories.

\section{Discussion and conclusions}

In this section, we first discuss the potential limitations of this study and present a selection of results from sensitivity studies. In the second part the main conclusions are presented together with a short list of open questions that follow from this first part of our WCB climatology. Some of these questions are addressed in Part II.

\section{a. Potential limitations}

This climatological study is based upon a specific dataset and a particular algorithm to identify WCBs and the question naturally arises whether the results are robust with respect to the choice of the data source and the WCB identification criteria. With respect to the reanalysis data the main issues are the overall quality of the model and data assimilation scheme, and the temporal and spatial resolution of the dataset. Given the fairly high resolution of the model version used for ERA-Interim and the 4D-Var data assimilation scheme, this reanalysis dataset is one of the state-of-theart products that are currently available to produce such a climatology. Comparison with WCB calculations using recent operational ECMWF analyses, which have a higher horizontal and vertical resolution (currently T1279 versus T255 used for ERA-Interim and 91 instead of 60 vertical levels), has shown that higher-resolution 

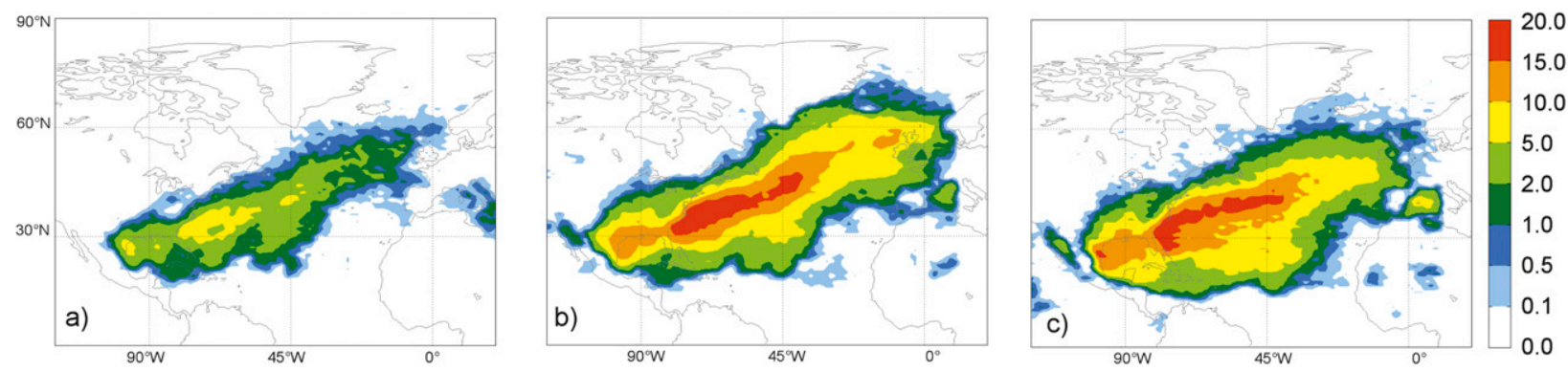

FIG. 12. Frequency of WCB trajectory starting points (i.e., positions at $t=0 \mathrm{~h}$ ) in the North Atlantic during DJF $1999 / 2000$ for three different selection criteria: (a) ascent of $600 \mathrm{hPa}$ in $48 \mathrm{~h}$, (b) ascent of $500 \mathrm{hPa}$ in $48 \mathrm{~h}$, and (c) ascent of $600 \mathrm{hPa}$ in $96 \mathrm{~h}$.

analyses tend to produce more trajectories that fulfill our WCB criterion of $600-\mathrm{hPa}$ ascent in $48 \mathrm{~h}$ compared to ERA-Interim. However the main WCB features are very similar in the two datasets. This indicates that quantitatively (i.e., in terms of the number of WCB trajectories) the climatology presented in this study is limited by the resolution of the reanalysis, but that the overall climatological pattern can be regarded as robust. Another concern is the 6-hourly resolution of the reanalyses, which can be a significant limitation for rapidly evolving weather systems. Some studies (e.g., Legras et al. 2003) used a combination of analyses and 3-hourly forecasts to double the temporal resolution of the wind fields. The latter effect is clearly beneficial; however, the very short-range forecast fields might suffer from spinup problems, leading to additional uncertainty for the trajectory calculations. Despite these limitations we trust that the ERA-Interim data allowed us to compile a high-quality WCB climatology covering the last three decades. Finally we mention the issue of parameterized convection. It is known from tracer studies (Agustí-Panareda et al. 2009) that a significant amount of tracer can be ventilated by parameterized convection processes along WCBs. This might not be equally relevant for all WCBs but is a process that is not well represented in global reanalyses and not explicitly captured by the trajectory calculations. Further investigations, using highresolution model simulations, on the effects of embedded convection in WCBs would be highly valuable.

The second main source of uncertainty stems from the identification algorithm. Our WCB trajectory selection criterion is motivated by earlier case studies, as mentioned in the introduction, but it nevertheless suffers from a certain degree of subjectivity. A threshold of $500 \mathrm{hPa}$ for the ascent within $48 \mathrm{~h}$, or an extension of the considered period of ascent, would of course both lead to an increased number of selected trajectories and would still be compatible with the general concept of WCBs as described in the pioneering papers by, for example, Harrold (1973) and Browning et al. (1973).
The key question is whether these modifications of the selection criteria would substantially change this study's results about the geographical distribution of WCBs and the evolution of key parameters along these airstreams. To address this question, we performed some additional calculations with altered selection criteria, 1) ascent of $500 \mathrm{hPa}$ within 2 days and 2) ascent of $600 \mathrm{hPa}$ within 4 days, for a particular region (the North Atlantic, as defined in Fig. 2) and one season (DJF 1999/2000). The general procedure (trajectory starting points, filtering to select real WCB trajectories) was not altered. Using our reference criterion of $600 \mathrm{hPa}$ within 2 days, $34229 \mathrm{WCB}$ trajectories are identified for the entire season. For the modified criteria, this number increases to 236664 and 131858 , respectively, which constitutes a massive increase. As expected the absolute number of trajectories is highly sensitive to the selection criterion, in particular to the ascent threshold. This leads to an increased frequency of WCB starting points at $t=0 \mathrm{~h}$ (Fig. 12). However, the spatial distribution does not change substantially. Noticeable is a slight poleward extension of the starting region for the reduced ascent and a slightly wider spread and equatorward extension for the longer ascent time period. With the latter criterion some trajectories are selected in the western Mediterranean. Also for the evolution of $q$, LWC, IWC, $\theta$, and PV as a function of pressure (not shown), the results are qualitatively very robust. Not surprisingly, with the reduced threshold for ascent, the average initial humidity is slightly smaller (about 7.2 instead of $8.5 \mathrm{~g} \mathrm{~kg}^{-1}$ at $900 \mathrm{hPa}$ ), as well as the peak LWC at about $750 \mathrm{hPa}$, and the integrated increase of potential temperature. The mean PV evolution is very similar for all three selection criteria, except of course for the fact that the low PV values hardly reach pressure levels above $350 \mathrm{hPa}$ with the reduced threshold for ascent. As discussed above, at this pressure level (and at lower altitudes), the typical PV value of the selected trajectories (about 0.3 PVU) does not constitute a very strong negative PV anomaly in contrast to the trajectories characterized by an ascent 
of at least $600 \mathrm{hPa}$. It is mainly for this reason that we regard our original WCB trajectory selection criterion as meaningful: it identifies strongly and rapidly ascending air parcels with maximum latent heating and the most substantial impact on the upper-level flow evolution.

\section{b. Main conclusions}

The present study presents a global WCB climatology using ERA-Interim data from 1979 to 2010. As in previous WCB studies, a Lagrangian approach has been used to identify WCB trajectories characterized by an ascent of at least $600 \mathrm{hPa}$ in $48 \mathrm{~h}$, which occurs in the vicinity of an extratropical cyclone. The main conclusions of this first multidecadal WCB climatology can be summarized as follows:

1) WCBs start their ascent mainly over the oceans within $20^{\circ}-47^{\circ} \mathrm{N}$ and $17^{\circ}-42^{\circ} \mathrm{S}$. In agreement with the previous climatology by Eckhardt et al. (2004), WCBs are more frequent in winter than in summer with a stronger seasonal cycle in the NH. Frequency peaks of WCBs are found in the NH storm track regions (mainly in DJF) and, throughout the year, in the lee of the Andes where a low-level jet transports moisture to the WCB inflow region. During the Indian monsoon period, moisture-laden winds are oriented toward the Himalaya range, leading to a high WCB frequency. Thus WCBs are particularly frequent in regions with intense baroclinicity and high low-level moisture content.

2) The 10-day backward extension of WCB trajectories reveals fairly widespread pathways to the regions of WCB ascent. In the SH transport from the subtropics typically dominates during this preascent phase, whereas the $\mathrm{NH}$ reveals strong seasonal variability with strong transport from the extratropics during winter and from the subtropics during summer. During the ascent, WCBs propagate rapidly poleward and eastward, and they fan out covering almost the entire extratropics during the 10 days after the WCB ascent phase.

3) The evolution of key variables along the WCB trajectories during their preascent, ascent, and postascent phases reveals the coherent nature of WCBs during their ascent. WCBs are moistened in the preascent phase and as they start to rise the specific humidity decreases strongly due to condensation and the formation of precipitation. Accordingly, during the ascent, there is first an increase in the liquid and then in the ice water content. At the end of the ascent (i.e., in the WCB's outflow regions) cloud ice is present, indicating the potential of WCBs to form cirrus clouds in the extratropical storm-track regions. The mean increase in potential temperature due to latent heating during the WCB ascent depends on the region and season and amounts to $18-38 \mathrm{~K}$, with the most pronounced increase during summer. WCB outflows occur between 313 and $321 \mathrm{~K}$ in winter and 333$346 \mathrm{~K}$ in summer, depending on the region considered.

4) Cloud diabatic processes modify PV during the WCB ascent leading to a robust $\mathrm{PV}$ evolution along $\mathrm{NH}$ WCBs with low PV values around 0.5 PVU in the low-tropospheric inflow, a positive anomaly in the midtroposphere, and again low values in the WCB outflow region (in the $\mathrm{SH}$ accordingly with negative $\mathrm{PV}$ values). The low-PV values in the WCB outflow correspond to intense negative PV anomalies due to the strong cross-isentropic ascent of WCBs to regions that are climatologically in the lower stratosphere. Diabatic PV changes along WCBs generate therefore positive PV anomalies at low levels, which are potentially important for the cyclone evolution, and strong negative anomalies at the tropopause level, which can have a strong impact upon the downstream flow evolution.

5) A detailed investigation of the diabatic PV production in the early phase of the WCB ascent reveals that 1) very strong positive PV anomalies occur preferentially along WCBs starting poleward of $40^{\circ}$ latitude indicating the importance of planetary vorticity for the diabatic PV modification; 2) for WCBs starting in the same region, relatively high initial PV (typically going along with high absolute vorticity) is important for an intense subsequent diabatic PV production; and 3) for WCBs starting in the same region and with similar initial PV values a strong vertical gradient of latent heating is crucial for a strong increase of PV. This analysis emphasizes that both the vertical gradient of the heating and absolute vorticity are important for the formation of low-level positive PV anomalies, but not necessarily the absolute humidity value in the inflow of WCBs.

These results corroborate the role of WCBs as key cross-isentropic airstreams, which are crucially important for the formation of mixed-phase clouds in the extratropical storm tracks, cirrus clouds in their outflow, and both positive PV anomalies in the lower and negative anomalies in the upper troposphere. Important open questions that follow from this analysis include the following: 1) What percentage of the global precipitation is associated with WCBs? 2) Do WCBs typically contribute to light and moderate intensity precipitation or do they also contribute to heavy precipitation events? 3) Where are the oceanic moisture sources of WCBs and 
what is the typical time period between ocean evaporation and condensation within WCBs? 4) What is the role of the positive PV anomalies produced in the early ascent phase of WCBs for the cyclone life cycle? 5) Do the negative PV anomalies in the WCB outflows contribute to the formation and/or maintenance of atmospheric blockings? 6) How important are mixed-phase and cirrus clouds formed along the WCB ascent and in the WCB outflow for the global cloud radiative forcing? 7) How well are WCBs simulated by global high-resolution weather prediction and lower-resolution climate models? 8) How sensitive is the PV evolution along WCBs to the models' cloud microphysical scheme? 9) How relevant are errors in the amplitude of and PV evolution along WCBs for the prediction of the downstream flow? Part II addresses the first three of these questions. Additional studies are underway to shed further light on the other aspects of this important midlatitude flow phenomenon.

Acknowledgments. MeteoSwiss and the ECMWF are acknowledged for providing access to the ERA-Interim data. We thank Maxi Böttcher, Stephan Pfahl, and Michael Sprenger for their valuable input to this study, and the three anonymous referees for their constructive comments. This project has been funded by the Swiss National Science Foundation (Project 200021-130079).

\section{REFERENCES}

Agustí-Panareda, A., S. L. Gray, and S. E. Belcher, 2009: On the dependence of boundary layer ventilation on frontal type. J. Geophys. Res., 114, D05305, doi:10.1029/2008JD010694.

Arnold, F., J. Schneider, K. Gollinger, H. Schlager, P. Schulte, D. Hagen, P. Whitefield, and P. van Velthoven, 1997: Observation of upper tropospheric sulfur dioxide- and acetonepollution: Potential implications for hydroxyl radical and aerosol formation. Geophys. Res. Lett., 24, 57-60.

BAFU, 1994: Die Hochwasser 1993 im Wallis und Tessin-Messdaten und ausgesuchte Auswertungen. Hydrologische Mitteilungen, LHG-19-D, 80 pp. [Available online at http://www.bafu.admin. ch/publikationen/publikation/00290/index.html?lang=de.]

Bethan, S., G. Vaughan, C. Gerbig, A. Volz-Thomas, H. Richer, and D. A. Tiddeman, 1998: Chemical air mass differences near fronts. J. Geophys. Res., 103 (D11), 13 413-13 434.

Bjerknes, J., and H. Solberg, 1922: Life cycle of cyclones and the polar front theory of atmospheric circulation. Geofys. Publ., 3, $1-18$.

Browning, K. A., 1990: Organization of clouds and precipitation in extratropical cyclones. Extratropical Cyclones: The Erik Palmén Memorial Volume, C. W. Newton and E. O. Holopainen, Eds., Amer. Meteor. Soc., 129-153.

_, and N. M. Roberts, 1994: Structure of a frontal cyclone. Quart. J. Roy. Meteor. Soc., 120, 1535-1557.

_ M. E. Hardman, T. W. Harrold, and C. W. Pardoe, 1973: The structure of rainbands within a mid-latitude depression. Quart. J. Roy. Meteor. Soc., 99, 215-231.
Buzzi, A., and L. Foschini, 2000: Mesoscale meteorological features associated with heavy precipitation in the southern alpine region. Meteor. Atmos. Phys., 72, 131-146.

Campetella, C., and C. Vera, 2002: The influence of the Andes mountains on the South American low-level flow. Geophys. Res. Lett., 29, 1826, doi:10.1029/2002GL015451.

Carlson, T. N., 1980: Airflow through midlatitude cyclones and the comma cloud pattern. Mon. Wea. Rev., 108, 1498-1509.

Chen, T., 2003: Maintenance of summer monsoon circulations: A planetary-scale perspective. J. Climate, 16, 2022-2037.

Davis, C. A., and K. A. Emanuel, 1991: Potential vorticity diagnostics of cyclogenesis. Mon. Wea. Rev., 119, 1929-1953.

Dee, D. P., and Coauthors, 2011: The ERA-Interim reanalysis: Configuration and performance of the data assimilation system. Quart. J. Roy. Meteor. Soc., 137, 553-597.

Ding, Y., and J. Chan, 2005: The East Asian summer monsoon: An overview. Meteor. Atmos. Phys., 89, 117-142.

Eckhardt, S., A. Stohl, H. Wernli, P. James, C. Forster, and N. Spichtinger, 2004: A 15-year climatology of warm conveyor belts. J. Climate, 17, 218-237.

Friedman, R., 1999: Constituting the polar front, 1919-1920. The Life Cycles of Extratropical Cyclones, M. Shapiro and S. Gronas, Eds., Amer. Meteor. Soc., 29-39.

Grams, C. M., and Coauthors, 2011: The key role of diabatic processes in modifying the upper-tropospheric wave guide: A North Atlantic case-study. Quart. J. Roy. Meteor. Soc., 137, 2174-2193.

Green, J. S. A., F. H. Ludlam, and J. F. R. McIlveen, 1966: Isentropic relative-flow analysis and the parcel theory. Quart. J. Roy. Meteor. Soc., 92, 210-219.

Harrold, T. W., 1973: Mechanisms influencing the distribution of precipitation within baroclinic disturbances. Quart. J. Roy. Meteor. Soc., 99, 232-251.

Hartmann, D. L., 1994: Global Physical Climatology. International Geophysics Series, Vol. 56, Academic Press, 441 pp.

Haynes, P. H., and M. E. McIntyre, 1987: On the evolution of vorticity and potential vorticity in the presence of diabatic heating and frictional or other forces. J. Atmos. Sci., 44, 828-841.

Holton, J. R., 2004: An Introduction to Dynamic Meteorology. International Geophysics Series, Vol. 88, Academic Press, 535 pp.

Hoskins, B. J., M. E. McIntyre, and A. W. Robertson, 1985: On the use and significance of isentropic potential vorticity maps. Quart. J. Roy. Meteor. Soc., 111, 877-946.

Insel, N., C. J. Poulsen, and T. A. Ehlers, 2010: Influence of the Andes Mountains on South American moisture transport, convection, and precipitation. Climate Dyn., 35, 1477-1492.

Joos, H., and H. Wernli, 2012: Influence of microphysical processes on the potential vorticity development in a warm conveyor belt: A case-study with the limited-area model COSMO. Quart. J. Roy. Meteor. Soc., 138, 407-418.

Knippertz, P., and J. E. Martin, 2005: Tropical plumes and extreme precipitation in subtropical and tropical West Africa. Quart. J. Roy. Meteor. Soc., 131, 2337-2365.

_ , and H. Wernli, 2010: A Lagrangian climatology of tropical moisture exports to the Northern Hemispheric extratropics. J. Climate, 23, 987-1003.

_,- , and G. Gläser, 2013: A global climatology of tropical moisture exports. J. Climate, 26, 3031-3045.

Lackmann, G., 2002: Cold-frontal potential vorticity maxima, the low-level jet, and moisture transport in extratropical cyclones. Mon. Wea. Rev., 130, 59-74.

Lau, W. K. M., D. E. Waliser, and B. N. Goswami, 2005: South Asian monsoon. Intraseasonal Variability in the AtmosphereOcean Climate System, Springer, 19-61. 
Legras, B., B. Joseph, and F. Lefèvre, 2003: Vertical diffusivity in the lower stratosphere from Lagrangian back-trajectory reconstructions of ozone profiles. J. Geophys. Res., 108, 4562, doi:10.1029/2002JD003045.

Martius, O., and H. Wernli, 2012: A trajectory-based investigation of physical and dynamical processes that govern the temporal evolution of the subtropical jet streams over Africa. J. Atmos. Sci., 69, 1602-1616.

— - E. Zenklusen, C. Schwierz, and H. C. Davies, 2006: Episodes of alpine heavy precipitation with an overlying elongated stratospheric intrusion: A climatology. Int. J. Climatol., 26, 1149-1164.

Massacand, A. C., H. Wernli, and H. C. Davies, 1998: Heavy precipitation on the alpine southside: An upper level precursor. Geophys. Res. Lett., 25, 1435-1438.

,$- \ldots$, and — 2001: Influence of upstream diabatic heating upon an alpine event of heavy precipitation. Mon. Wea. Rev., 129, 2822-2828.

Mendes, D., E. P. Souza, I. F. Trigo, and P. M. A. Miranda, 2007: On precursors of South American cyclogenesis. Tellus, 59A, 114-121.

Ninomiya, K., and Y. Shibagaki, 2007: Multi-scale features of the Meiyu-Baiu front and associated precipitation systems. J. Meteor. Soc. Japan, 85B, 103-122.

Pfahl, S., E. Madonna, M. Boettcher, H. Joos, and H. Wernli, 2014: Warm conveyor belts in the ERA-Interim dataset (19792010). Part II: Moisture origin and relevance for precipitation. J. Climate, 27, 27-40.

Pomroy, H. R., and A. J. Thorpe, 2000: The evolution and dynamical role of reduced upper-tropospheric potential vorticity in intensive observing period one of FASTEX. Mon. Wea. Rev., 128, 1817-1834.

Reed, R., 1990: Advances in knowledge and understanding of extratropical cyclones during the past quarter century: An overview. Extratropical Cyclones: The Erik Palmén Memorial Volume, C. Newton and E. Holopainen, Eds., Amer. Meteor. Soc., 129-153.

— pause. Arch. Meteor. Geophys. Bioklimatol., A11, 1-17.

Schemm, S., H. Wernli, and L. Papritz, 2013: Warm conveyor belt in idealized moist baroclinic wave simulation. J. Atmos. Sci., 70, 627-652.

Sickmöller, M., R. Blender, and K. Fraedrich, 2000: Observed winter cyclone tracks in the northern hemisphere in re-analysed ECMWF data. Quart. J. Roy. Meteor. Soc., 126, 591-620.
Simmonds, I., and K. Keay, 2000: Mean Southern Hemisphere extratropical cyclone behavior in the 40-year NCEP-NCAR reanalysis. J. Climate, 13, 873-885.

Simmons, A., S. Uppala, D. Dick, and K. Shinya, 2006: ERAInterim: New ECMWF reanalysis products from 1989 onwards. ECMWF Newsletter, No. 110, ECMWF, Reading, United Kingdom, 25-35.

Sinclair, M. R., 1995: A climatology of cyclogenesis for the Southern Hemisphere. Mon. Wea. Rev., 123, 1601-1619.

Sinclair, V. A., S. L. Gray, and S. E. Belcher, 2008: Boundary-layer ventilation by baroclinic life cycles. Quart. J. Roy. Meteor. Soc., 134, 1409-1424.

Stoelinga, M. T., 1996: A potential vorticity-based study of the role of diabatic heating and friction in a numerically simulated baroclinic cyclone. Mon. Wea. Rev., 124, 849-874.

Stohl, A., 2001: A 1-year Lagrangian "climatology" of airstreams in the Northern Hemisphere troposphere and lowermost stratosphere. J. Geophys. Res., 106 (D7), 7263-7279.

_ - and T. Trickl, 1999: A textbook example of long-range transport: Simultaneous observation of ozone maxima of stratospheric and North American origin in the free troposphere over Europe. J. Geophys. Res., 104 (D23), 30445 30462.

_ S. Eckhardt, C. Forster, P. James, and N. Spichtinger, 2002: On the pathways and timescales of intercontinental air pollution transport. J. Geophys. Res., 107, 4684, doi:10.1029/ 2001JD001396.

Vera, C. S., P. K. Vigliarolo, and E. H. Berbery, 2002: Cold season synoptic-scale waves over subtropical South America. Mon. Wea. Rev., 130, 684-699.

Wernli, H., 1997: A Lagrangian-based analysis of extratropical cyclones. II: A detailed case-study. Quart. J. Roy. Meteor. Soc., 123, 1677-1706.

_ _ and H. C. Davies, 1997: A Lagrangian-based analysis of extratropical cyclones. I: The method and some applications. Quart. J. Roy. Meteor. Soc., 123, 467-489.

__ and M. Bourqui, 2002: A Lagrangian "1-year climatology" of (deep) cross-tropopause exchange in the extratropical Northern Hemisphere. J. Geophys. Res., 107, 4021, doi:10.1029/ 2001JD000812.

— taset (1958-2001). Part I: Novel identification method and global climatology. J. Atmos. Sci., 63, 2486-2507. 